\title{
Differences in photosynthetic responses of NADP-ME type C4 species to high light
}

\author{
Elżbieta Romanowska ${ }^{1}$ • Alicja Buczyńska ${ }^{1} \cdot$ Wioleta Wasilewska $^{1} \cdot$ \\ Tomasz Krupnik $^{1}$ Anna Drożak ${ }^{1} \cdot$ Paweł Rogowski $^{1}$ Eugeniusz Parys ${ }^{1}$ • \\ Maksymilian Zienkiewicz ${ }^{1}$
}

Received: 25 July 2016/Accepted: 20 September 2016/Published online: 18 December 2016

(c) The Author(s) 2016. This article is published with open access at Springerlink.com

\begin{abstract}
Main conclusion Three species chosen as representatives of NADP-ME C4 subtype exhibit different sensitivity toward photoinhibition, and great photochemical differences were found to exist between the species. These characteristics might be due to the imbalance in the excitation energy between the photosystems present in $M$ and BS cells, and also due to that between species caused by the penetration of light inside the leaves. Such regulation in the distribution of light intensity between $M$ and BS cells shows that co-operation between both the metabolic systems determines effective photosynthesis and reduces the harmful effects of high light on the degradation of PSII through the production of reactive oxygen species (ROS).
\end{abstract}

Abstract We have investigated several physiological parameters of NADP-ME-type C4 species (e.g., Zea mays, Echinochloa crus-galli, and Digitaria sanguinalis) grown under moderate light intensity $(200 \mu \mathrm{mol}$ photons $\mathrm{m}^{-2} \mathrm{~s}^{-1}$ ) and, subsequently, exposed to excess light intensity (HL, $1600 \mu \mathrm{mol}$ photons $\mathrm{m}^{-2} \mathrm{~s}^{-1}$ ). Our main interest was to understand why these species, grown under identical conditions, differ in their responses toward high light, and what is the physiological significance of these differences. Among the investigated species, Echinochloa crus-galli is best adapted to HL treatment. High resistance of the photosynthetic apparatus of $E$. crus-galli to HL was

Elżbieta Romanowska

romanela@biol.uw.edu.pl

1 Department of Molecular Plant Physiology, Faculty of

BiologyUniversity of Warsaw, Miecznikowa 1,

02-096 Warsaw, Poland accompanied by an elevated level of phosphorylation of PSII proteins, and higher values of photochemical quenching, ATP/ADP ratio, activity of PSI and PSII complexes, as well as integrity of the thylakoid membranes. It was also shown that the non-radiative dissipation of energy in the studied plants was not dependent on carotenoid contents and, thus, other photoprotective mechanisms might have been engaged under HL stress conditions. The activity of the enzymes superoxide dismutase and ascorbate peroxidase as well as the content of malondialdehyde and $\mathrm{H}_{2} \mathrm{O}_{2}$ suggests that antioxidant defense is not responsible for the differences observed in the tolerance of NADP-ME species toward HL stress. We concluded that the chloroplasts of the examined NADP-ME species showed different sensitivity to short-term high light irradiance, suggesting a role of other factors excluding light factors, thus influencing the response of thylakoid proteins. We also observed that HL affects the mesophyll chloroplasts first hand and, subsequently, the bundle sheath chloroplasts.

Keywords Bundle sheath and mesophyll chloroplasts . Fluorescence - Photosynthesis rate - Protein phosphorylation $\cdot$ Photosystems activity $\cdot$ Photoinhibition

\begin{tabular}{|c|c|}
\hline \multicolumn{2}{|c|}{ Abbreviations } \\
\hline APX & Ascorbate peroxidase \\
\hline BS & Bundle sheath \\
\hline ETR & Relative electron transport rate \\
\hline$F \mathrm{v} / F \mathrm{~m}$ & $\begin{array}{l}\text { Ratio of variable to maximum chlorophyll } \\
\text { fluorescence }\end{array}$ \\
\hline $\mathrm{HL}$ & High light \\
\hline LHCII & $\begin{array}{l}\text { Chlorophyll } a \text {-/ } b \text {-binding protein of } \\
\text { photosystem II }\end{array}$ \\
\hline M & Mesophyll \\
\hline
\end{tabular}




$\begin{array}{ll}\text { MDA } & \text { Malondialdehyde } \\ \text { ML } & \text { Moderate light } \\ \text { NADP-ME } & \text { NADP-depended malic enzyme } \\ \text { NPQ } & \text { Non-photochemical quenching } \\ \text { SOD } & \text { Superoxide dismutase }\end{array}$

\section{Introduction}

In the leaves of $\mathrm{C} 4$ plants, the photosynthetic apparatus is partitioned between two cell types that are anatomically and biochemically distinct: bundle sheath (BS) and mesophyll (M) cells. These cells differ in their morphology as well as in the structure and specialization of their thylakoid membranes (Hatch 1987; Friso et al. 2010). Based on the differences of the major decarboxylation enzymes present in BS cells, C4 plants are classified into three biochemical subtypes: NADP-ME, NAD-ME, and PEP-CK (Hatch et al. 1975; Sheen 1999), where the NADP-ME species possesses structurally dimorphic chloroplasts. $\mathrm{M}$ chloroplasts are similar to those reported for other species of higher plants, whereas BS chloroplasts are characterized by highly reduced grana and various amounts of photosystems, and their photochemical activity, which may be related to the species or the habitat of these plants (Furbank and Foyer 1988). It is known that maize bundle sheath chloroplasts have the most reduced granal stacking (Taniguchi et al. 2003). Their level of photosystem II (PSII) in BS is relatively low and they contain mostly photosystem I (PSI). Although the PSII in BS membranes contains all the polypeptides involved in electron transport and oxygen evolution, it is practically inactive (Romanowska et al. 2006, 2008; Drożak and Romanowska 2006). Earlier, it was suggested that the agranal BS chloroplasts of maize are typical for the genus and do not appear to be influenced by irradiance (Downton and Pyliotis 1971). There have been also other reports on the functional PSII in bundle sheath chloroplasts of maize, claiming up to $50 \%$ of the wholechain electron transport capacity seen in the thylakoids of C3 plants (Hardt and Kok 1978; Walker and Izawa 1979). It was also demonstrated that the level of the PSII in maize is regulated by the synthesis of key core components (Meierhoff and Westhoff 1993), and it has been postulated that the PSII content of the BS chloroplasts may be proportional to the amount of the aspartate transported from mesophyll (Chapman and Hatch 1981; Meister et al. 1996). Pengelly et al. (2010) suggested that an increased PSII content observed in both $\mathrm{M}$ and BS chloroplasts of Flaveria bidentis in low light might be due to the adaptation of PSII to growth light irradiance. Regulation of PSII levels in BS chloroplasts has not yet been extensively examined; therefore, maize chloroplasts may be considered as an appropriate model to study the relationship between structure and function in thylakoid membranes affected by various environmental factors. The opposite examples to BS chloroplasts in maize could be other NADP-ME species, such as Echinochloa crus-galli and Digitaria sanguinalis, representing the scope of variation in abundance of grana in BS chloroplasts (Ueno et al. 2005). There is a lack of information about the effects of light conditions on photochemistry of M and BS chloroplasts of these species, hence they are an interesting system for comparative studies of the response of these chloroplasts in varying light conditions. Due to the differences observed in both $\mathrm{M}$ and BS chloroplasts function, specific mechanisms are required to adjust the photosynthetic activity, upon variation in light quality and intensity.

Chloroplasts are plant organelles that are most sensitive to various stress factors, and light is one of the most important factors promoting a specific rearrangement of the chloroplast machinery in response to changes in its intensity and quality. In previous studies, we have revealed that the response of C3- and C4-type plants depends on both light quality and quantity, which was confirmed by the differences observed in light saturation of the investigated chloroplasts according to the light-penetration profile of the leaves (Zienkiewicz et al. 2015). When a leaf is exposed to light intensities exceeding their photosynthetic capacity, a decrease in the yield of chlorophyll fluorescence occurs, as part of the loss of excitation energy in the form of heat (non-photochemical quenching, NPQ) (Krause and Weis 1991). An increase in the levels of NPQ, while exposed to light irradiation, is correlated to a decline in the quantum yield of photosynthesis (Genty et al. 1989). The component of NPQ responsible for transthylakoidal membrane proton gradient activates violaxanthin de-epoxidase, thereby increasing zeaxanthin formation which in turn is involved in fluorescence quenching. Presumably, the thermal dissipation of energy is the main way of deactivating PSII under high light conditions since photorespiration in $\mathrm{C} 4$ plants is inhibited. Because Zea mays has a smaller pool of xanthophyll cycle pigments compared to $\mathrm{C} 3$ plants, the nonradiative energy dissipation is not univocally dependent on the zeaxanthin content, and other photoprotective mechanisms may be involved under stress by high light irradiance (Brugnoli et al. 1994). It seems, therefore, that the antioxidant metabolism can be implicated in determining the sensitivity of NADP-ME-type C4 plants to light stress, and its precise mechanism is more complicated compared to $\mathrm{C} 3$ plants. The $\mathrm{M}$ and $\mathrm{BS}$ cells have different antioxidant capacity (Doulis et al. 1997; Pastori et al. 2000). Some enzymes such as catalase are equally distributed between the two cell types, whereas ascorbate peroxidase (APX) and superoxide dismutase (SOD) are mainly localized in BS cells (Foyer et al. 2002). Such partitioning of antioxidants in the M and BS cells can minimize the accumulation 
of active oxygen species and is essential for plant homeostasis. The intercellular specialization helps in the efficient operation of photosynthesis, in particular stress conditions. The exposure of plants to high light can limit the electron transport, increase photoinhibition, and decrease the photosynthetic efficiency associated with PSII damage (Ohnishi et al. 2005; Hakala et al. 2006; Nishiyama et al. 2006).

To minimize photodamage, plants have developed protective mechanisms, such as rapid movement of leaves and chloroplasts, reversible phosphorylation of the thylakoid proteins, or state transitions. Also changes in the LHC protein level and modification of the leaf structure, morphology, or composition may occur (Givnish 1988; Ruban 2009). State transitions are the principal types of responses to changes in light quality, which are different from lightharvesting regulation induced by changes in light intensity (Minagawa 2011), whereas photoinhibition is caused by an imbalance between the rates of the damage and repair cycle of photosystem II proteins in thylakoid membranes. Lack of Calvin cycle in $\mathrm{M}$ chloroplasts and much lower generation of NADPH in BS chloroplasts compared to M cells may disturb the redox status established between the two cells types, and depending on the metabolic conditions, they may also contribute to PSII photoinhibition (Furbank and Foyer 1988). Phosphorylation of several PSII core subunits and LHCII proteins depends on the light intensity and their interactions with kinases and phosphatases (Baena-Gonzalez et al. 1999; Pribil et al. 2010; Shapiguzov et al. 2010). The phosphorylation of core proteins depends on light intensity, which was confirmed by the increased level of phosphorylation observed in high light conditions (Baena-Gonzalez et al. 1999). Phosphorylation of D1 protein is implicated in the regulation of this protein degradation (Rintämaki et al. 1996). The regulation of the repair cycle of PSII in BS compared to M thylakoid membranes of high light-treated $\mathrm{C} 4$ plants is not yet well known (Pokorska et al. 2009). All acquired data come from the experiments performed on Z. mays, and it is unknown whether other NADP-ME species show the same response to HL. Phosphorylation of LHCII proteins is responsible for the redistribution of the absorbed light energy between two photosystems (Rintamäki et al. 2000). The reversible phosphorylation of LHCII regulates the relative rates of the cyclic and noncyclic electron transport in chloroplasts and, thereby, it balances the rates of synthesis of ATP and NADPH with the demands of the Calvin cycle and of other metabolic pathways operating within the organelle (Grieco et al. 2015). High ATP concentration in the chloroplasts increases protein phosphorylation, while simultaneously inhibiting phosphatases (Rintämaki et al. 1996). The ATP level can also affect the activity of chloroplast proteases (Lindahl et al. 2000). It remains largely unknown to what extent the $\mathrm{C} 4$ plants coordinate the energy distribution between the $\mathrm{M}$ and $\mathrm{BS}$ chloroplasts, associated with response to changes in light intensity/quality.

The aim of this study was to investigate whether the chloroplasts of Z. mays, D. sanguinalis, and E. crus-galli, all NADP-ME-type C4 plants, possess the same mechanisms capable of inducing similar responses to high light conditions, thereby maintaining high photosynthetic efficiency. The question regards the mechanism by which the NADP-ME plants maintain the light reaction with maximal efficiency under photoinhibitory light treatment. For the first time, we reported that three NADP-ME species cultivated under the same conditions differ in their photosynthetic and respiratory responses to high light treatment. Our results indicated that out of the three investigated species, E. crus-galli was the most impervious to high light (HL) treatment, and possible reasons for its higher tolerance toward photoinhibitory light treatment are discussed. High resistance of photosynthetic processes to HL in E.crus-galli plants positively correlates with the phosphorylation level of PSII protein subunits, higher values of photochemical quenching and ATP/ADP ratio, organization of PSI and PSII complexes, as well as integrity of the thylakoid membranes.

These data provide a novel insight into the relations between differential membrane structure and function in thylakoids of $\mathrm{M}$ and BS chloroplasts of the NADP-MEtype species and show different mechanisms preventing photoinhibition. We believe that some of our observations may serve as a baseline for further exploration of the $\mathrm{C} 4$ photosynthetic metabolism important for the introduction of the C4-type pathway into the C3-type plants such as rice in order to maximize their productivity.

\section{Materials and methods}

\section{Plant material and growth conditions}

Maize seeds (Z. mays L.) were provided by the Plant Breeding and Acclimatization Institute (IHAR)-National Research Institute (Radzików, Poland); seeds of D. sanguinalis and E. crus-galli were collected from plants growing in the field near Warsaw (Walendów, Poland). NADP-ME-type C4 plants: Z. mays was grown in vermiculite, whereas D. sanguinalis and Echinochloa crus-galli plants were grown hydroponically in aerated Knop's solution. Maize plants were fertilized with Knop's solution containing $\left(\mathrm{g} \mathrm{L}^{-1}\right) \quad 0.8 \quad \mathrm{CaNO}_{3} \cdot 4 \mathrm{H}_{2} \mathrm{O}, 0.2 \quad \mathrm{KNO}_{3}, 0.2$ $\mathrm{KH}_{2} \mathrm{PO}_{4}, 0.2 \mathrm{MgSO}_{4} \cdot 7 \mathrm{H}_{2} \mathrm{O}$, and 0.028 EDTA-Fe enriched with $\mathrm{A}-\mathrm{Z}$ microelement nutrients. Plants were grown in a growth chamber with a $14 \mathrm{~h}$ long irradiation photoperiod and a day/night regime at $24 / 21{ }^{\circ} \mathrm{C}$ at an irradiance of 
$200 \mu \mathrm{mol}$ photons $\mathrm{m}^{-2} \mathrm{~s}^{-1}$ (ML). Detached leaves from plants were placed in water and transferred to high light (HL, $1600 \mu \mathrm{mol}$ photons $\mathrm{m}^{-2} \mathrm{~s}^{-1}$ ) for $1 \mathrm{~h}$ at $25^{\circ} \mathrm{C}$ prior further measurements and thylakoid isolation. Only photosynthesis rate $(\mathrm{Pn})$ was measured every $20 \mathrm{~min}$ throughout $2 \mathrm{~h}$ in the leaves previously illuminated by photoinhibitory light (HL). Leaves were harvested from 4to 5-week-old plants.

\section{Chloroplast and thylakoids isolation}

Mesophyll and bundle sheath chloroplasts were isolated mechanically according to the procedure by Romanowska et al. (2006). Isolation procedures were carried out at $4{ }^{\circ} \mathrm{C}$, under dim green light. The isolation buffers were supplemented with $10 \mathrm{mM} \mathrm{NaF}$ as a phosphatase inhibitor. Thylakoids were prepared by washing $\mathrm{M}$ and BS chloroplasts in a medium containing $50 \mathrm{mM}$ Hepes- $\mathrm{NaOH}(\mathrm{pH}$ 7.5), $5 \mathrm{mM} \mathrm{MgCl} 2,10 \mathrm{mM} \mathrm{NaCl}, 2 \mathrm{mM}$ EDTA, $10 \mathrm{mM}$ $\mathrm{NaF}$, and collected by centrifugation at $8000 \mathrm{~g}$ for $15 \mathrm{~min}$. Isolated thylakoid samples were immediately frozen in liquid nitrogen and stored at $-80{ }^{\circ} \mathrm{C}$ until use. The purity of chloroplasts was monitored by measuring the chlorophyll $a / b$ ratio, enzymatic assays, and immunodetection of selected proteins, as described in Romanowska and Parys (2010).

\section{Measurements of PSI and PSII electron transfer activity}

PSII activity of M and BS thylakoids of Z. mays, D. sanguinalis, and E. crus-galli was monitored spectrophotometrically as dichlorophenol-indophenol (DCPIP) photoreduction as described in Mamedov et al. (2000). Photoreduction was measured as the decrease in absorbance at $590 \mathrm{~nm}$ in a medium containing $330 \mathrm{mM}$ sorbitol, $40 \mathrm{mM}$ Hepes- $\mathrm{KOH}$ (pH 7.6), $1 \mathrm{mM} \mathrm{KH}_{2} \mathrm{PO}_{4}, 5 \mathrm{mM}$ $\mathrm{NaCl}, 5 \mathrm{mM} \mathrm{MgCl} 2,5 \mathrm{mM} \mathrm{NH}_{4} \mathrm{Cl}$, and $0.1 \mathrm{mM}$ DCPIP. The applied light was at an intensity of $1000 \mu$ mol photons $\mathrm{m}^{-2} \mathrm{~s}^{-1}$. Earlier, we had found similar PSII activities for the light irradiances in the range 600-3000 $\mu$ mol photons $\mathrm{m}^{-2} \mathrm{~s}^{-1}$ (Pokorska and Romanowska 2007). The absorbance was read at $30 \mathrm{~s}$ intervals during the 1-min assays. The total volume of the reaction mixture was $2 \mathrm{ml}$ including the chloroplast sample of $20 \mu \mathrm{g} \mathrm{Chl}$.

PSI activity was measured using a Clark oxygen electrode (TriOximatic EO200; WTW, Weilheim, Germany). After 3 min of adaptation of the isolated thylakoids in the dark, activity was measured at $25{ }^{\circ} \mathrm{C}$ at $1000 \mu$ mol photons $\mathrm{m}^{-2} \mathrm{~s}^{-1}$. The total volume of $2 \mathrm{~mL}$ of the reaction mixture contained $50 \mathrm{mM}$ Hepes-KOH (pH 7.7), $100 \mathrm{mM}$ sorbitol, $2 \mathrm{mM}$ EDTA, $1 \mathrm{mM} \mathrm{KCl}$, and $5 \mathrm{mM} \mathrm{MgCl}_{2}$. PSI activity was measured as oxygen uptake in the reduction reaction of
$0.2 \mathrm{mM}$ TMPD (tetramethyl-p-phenylene diamine) with $3 \mathrm{mM}$ ascorbate as the electron donor and $0.1 \mathrm{mM}$ methylviologen (MV) as the final electron acceptor; $10 \mathrm{mM}$ 3-(3,4-dichlorophenyl)-1,1-dimethylurea (DCMU) and $5 \mathrm{mM} \mathrm{NaN}_{3}$ were used as the PSII and catalase inhibitor, respectively. For electron transport measurements, chloroplast suspension containing $30 \mu \mathrm{g}$ of chlorophyll was added to the reaction mixture.

All results are presented as mean values \pm standard error (SE). The significant differences between means were determined using Student's $t$ test for paired observations at a confidence level of $\alpha=0.05$.

\section{SDS-PAGE and immunodetection analysis}

Denaturing SDS-polyacrylamide gel electrophoresis was carried out according to Laemmli (1970). Thylakoid samples were diluted in the denaturing buffer $(1 / 1, \mathrm{v} / \mathrm{v})$ containing $0.25 \mathrm{M}$ Tris- $\mathrm{HCl}(\mathrm{pH} 6.8), 4 \%$ (w/v) SDS, $10 \mathrm{M}$ urea, 2\% (v/v) 2-mercaptoethanol, and 20\% (v/v) glycerol. Separating gel (15\% acrylamide) contained $6 \mathrm{M}$ urea. Gels were loaded with thylakoid samples on an equal Chl basis. For immunoblotting analysis, the proteins resolved by SDS-PAGE were electrotransferred onto a PVDF membrane (Millipore, Badford, MA, USA) using $25 \mathrm{mM}$ Tris, $192 \mathrm{mM}$ glycine ( $\mathrm{pH} 8.3$ ), and $10 \%(\mathrm{v} / \mathrm{v})$ methanol in the transfer buffer, as described by Towbin et al. (1979). The blocking was done with $5 \%$ fatty acid-free albumin (Sigma-Aldrich). Blots were probed with D1 (Agrisera, Vännäs, Sweden, AS05 084) and antiphosphotreonine (anti-P-Thr) antibodies (Cell Signalling Technology, \#9381). The membranes were incubated with horseradish peroxidase-conjugated secondary antibody (Agrisera, Vännäs, Sweden, AS09 602), and cross-reacting protein bands were visualized by enhanced chemiluminescence according to the standard procedures using Chemi Doc System (Bio-Rad).

\section{Blue native (BN)-PAGE}

Protein solubilization and BN-PAGE were performed according to Schägger (2001) and Kügler et al. (1997) with slight modifications. Thylakoid membranes $(45 \mu \mathrm{g} \mathrm{Chl})$ were sedimented at $7000 \mathrm{~g}$ for $5 \mathrm{~min}$ at $4{ }^{\circ} \mathrm{C}$ and resuspended in a buffer composed of $5 \mathrm{mM}$ 6-aminohexanoic acid (EACA), $50 \mathrm{mM}$ imidazole- $\mathrm{HCl}(\mathrm{pH} 7.0), 50 \mathrm{mM}$ $\mathrm{NaCl}$, and $0.5 \mathrm{mM}$ EDTA. Membrane proteins were solubilized by the addition of $n$-dodecyl $\beta$-D-maltoside (DDM) to a final concentration of $1 \%$ for $\mathrm{M}$ and $2 \%$ for BS thylakoids (w/v). Samples were incubated on ice for $5 \mathrm{~min}$ and centrifuged at $15,800 \mathrm{~g}$ for $40 \mathrm{~min}$. The supernatant was supplemented with Coomassie Brilliant Blue solution (100 mM EACA, 30\% sucrose) to a final concentration of 
$10 \%$ and loaded directly onto $4-10 \%$ acrylamide and 4-15\% sucrose gradient gel. Electrophoresis was carried out using constant voltage of $100 \mathrm{~V}$ at $4{ }^{\circ} \mathrm{C}$. The results shown on the gels are representative of those obtained in at least three independent experiments.

\section{Measurements of $\mathrm{CO}_{2}$ exchange}

The $\mathrm{CO}_{2}$ exchange was measured as described earlier (Romanowska et al. 2002; Parys et al. 2004) using infrared $\mathrm{CO}_{2}$ analyzer (Beckman 865). The middle segments of leaves were placed into a plexiglas photosynthetic chamber in a bag containing water. Temperature was $22 \pm 1{ }^{\circ} \mathrm{C}$ during the dark and light periods. Respiration rate before photosynthesis $\left(R_{0}\right)$ was determined in leaves adapted to darkness for $10 \mathrm{~h}$. Then, the leaves were exposed to light (400 $\mu \mathrm{mol}$ photons $\mathrm{m}^{-2} \mathrm{~s}^{-1}$ ) and photosynthesis (Pn) was measured. The respiration following photosynthesis $\left(R_{1}\right)$ was determined after 2-3 min of darkness, which represents the light-enhanced dark respiration (LEDR). Pn was also measured every $20 \mathrm{~min}$ throughout $2 \mathrm{~h}$ in the leaves previously illuminated by photoinhibitory light ( $1 \mathrm{~h}$ of $1600 \mu \mathrm{mol}$ photons $\mathrm{m}^{-2} \mathrm{~s}^{-1}$, HL). The photosynthesis and respiration rates were calculated from the changes in $\mathrm{CO}_{2}$ concentration in the range $360-300 \mu \mathrm{L} \mathrm{L}^{-1}$. The rates of photosynthesis and respiration were expressed in relation to leaf area.

\section{In vivo measurement of chlorophyll a fluorescence}

Simultaneous measurements of photosynthesis and Chl $a$ fluorescence of the same part of the leaf of Z. mays, $D$. sanguinalis, and E. crus-galli were performed at room temperature with a fluorometer (FMS 1, Hansatech, UK) run by Modfluor software. Leaves were adapted to the dark for $30 \mathrm{~min}$ prior to measurements of maximum quantum efficiency of PSII photochemistry $(F \mathrm{v} / F \mathrm{~m})$, and then they were irradiated with a saturating light of $4500 \mu \mathrm{mol}$ photons $\mathrm{m}^{-2} \mathrm{~s}^{-1}$. Photochemical quenching (qP) and nonphotochemical quenching (NPQ) were also measured according to the procedure of Genty et al. (1989) using actinic irradiation of 400 and $1020 \mu \mathrm{mol}$ photons $\mathrm{m}^{-2} \mathrm{~s}^{-1}$. The standard amber-modulating beam had a center frequency of $594 \mathrm{~nm}$. Fluorescence parameters were assayed for the leaves from growth conditions (ML) and after transffering them from ML to high light (HL) for $1 \mathrm{~h}$.

In addition, the relative electron transport rates (ETR) were measured in the light, using a pulse amplitude modulated (PAM) fluorometry (DUAL-PAM-100 system Walz, Effeltrich, Germany) in the leaves of plants grown under ML and after $1 \mathrm{~h}$ high light (HL) treatment. ETR was measured as a function of irradiance. The duration of the irradiance pulse at each level of actinic light was set to
$60 \mathrm{~s}$. All results are represented as mean $\pm \mathrm{SE}$ of 10 independent series of experiments (6-8 measurements each).

\section{Determination of ATP content in whole leaves}

The leaf samples were prepared as described by Romanowska et al. (2002). The leaves were cut and immediately ground in liquid nitrogen. The powder obtained was treated with $10 \%(\mathrm{v} / \mathrm{v}) \mathrm{HClO}_{4}$ and left for $5 \mathrm{~min}$ on ice. The icecooled samples were centrifuged at $10,000 \mathrm{~g}$ for $2 \mathrm{~min}$ and aliquots of the supernatants were brought to $\mathrm{pH} 7.0$ by adding $1 \mathrm{M}$ triethanolamine in $5 \mathrm{M} \mathrm{KOH}$. After $30 \mathrm{~min}$ on ice, the precipitated $\mathrm{KClO}_{4}$ was pelleted $(10,000 \mathrm{~g}$ for $2 \mathrm{~min}$ ), and the adenylate contents were measured in the supernatants. ATP was determined by the firefly luciferase method (Gardeström and Wigge 1988). ADP was converted to ATP by pyruvate kinase (Boehringer, Mannheim, Germany) and determined as above. Each measurement was calibrated with an addition of ATP standard. The measurements were repeated at least three times in three to four separate experiments.

\section{Carotenoid analysis}

Analytical high-pressure liquid chromatography (HPLC) was performed according to the modified method of Krupnik et al. (2013) using a maximum flow rate of $0.6 \mathrm{~mL} \mathrm{~min}{ }^{-1}$ and a Nucleosil $100 \mathrm{C} 18$ column (Teknokroma, Barcelona, Spain). Pigments were extracted twice from the isolated thylakoid samples $(0.5 \mathrm{mg} \mathrm{Chl})$ with $1 \mathrm{ml}$ of acetone:methanol $(7: 2, \mathrm{v} / \mathrm{v})$ mixture. The volume of the thylakoid membrane suspension was no greater than one-fourth of the extraction mixture. Cellular and protein debris was removed by centrifugation at $4{ }^{\circ} \mathrm{C}$ (10,000 $\mathrm{g}$ for $10 \mathrm{~min})$. The extract was concentrated in a SpeedVac at $30{ }^{\circ} \mathrm{C}$ to $\mathrm{Chl} a$ concentration of $1 \mathrm{mg} \mathrm{mL}^{-1}$. Concentrated samples $(20 \mu \mathrm{g}$ Chl $)$ were loaded onto the C18 column, previously equilibrated with phase A (acetonitrile:water:triethylamine, 90:10:0.1, by vol.). Pigments were separated in a linear gradient of $10-60 \%$ of phase B (ethyl acetate). Chlorophylls and carotenoid pigments were detected by absorbance at $436 \mathrm{~nm}$. The content of each carotenoid species was expressed as a ratio of the area underneath the pigment-corresponding peak to the area under the Chl $a$ peak. The amounts of each carotenoid were estimated using the extinction coefficient proposed by Davies (1976). Pigment molar ratios (in acetonitrile) were calculated using extinction coefficients $134.7 \mathrm{mM}^{-1} \mathrm{~cm}^{-1}$ for neoxanthin, $122.9 \mathrm{mM}^{-1} \mathrm{~cm}^{-1}$ for violaxanthin, $128.3 \mathrm{mM}^{-1} \mathrm{~cm}^{-1}$ for antheraxanthin, $133.3 \mathrm{mM}^{-1} \mathrm{~cm}^{-1}$ for zeaxanthin, $136.1 \mathrm{mM}^{-1} \mathrm{~cm}^{-1}$ for lutein, $56 \mathrm{mM}^{-1}$ $\mathrm{cm}^{-1}$ for Chl $b, 91.7 \mathrm{mM}^{-1} \mathrm{~cm}^{-1}$ for Chl $a$, and $134.6 \mathrm{mM}^{-1} \mathrm{~cm}^{-1}$ for $\beta$-carotene. 


\section{Other determinations}

Total chlorophyll content was determined in $80 \%(\mathrm{v} / \mathrm{v})$ acetone according to Porra (2002). Protein was assayed according to Bradford (1976). The activity of ascorbate peroxidase (APX) and superoxide dismutase (SOD), and the amount of hydrogen peroxide $\left(\mathrm{H}_{2} \mathrm{O}_{2}\right)$ and malondialdehyde (MDA) were assayed as described by Parys et al. (2014).

\section{Results}

NADP-ME plants Z. mays, D. sanguinalis, and E. crusgalli were grown under moderate light (ML, $200 \mu \mathrm{mol}$ photons $\mathrm{m}^{-2} \mathrm{~s}^{-1}$ ) and their responses to photoinhibitory light $\left(\mathrm{HL}, 1600 \mu \mathrm{mol}\right.$ photons $\mathrm{m}^{-2} \mathrm{~s}^{-1}$ ) were studied. Fluorescence in vivo, gas exchange, and ATP/ADP ratio of the leaves were measured.

\section{Effect of HL treatment on photosynthesis, respiration, and $\mathrm{Chl} a$ fluorescence in vivo}

To determine changes in the short-term response of photosynthesis, characteristics of photosynthesis, respiration, and fluorescence of the leaves from three species growing in $\mathrm{ML}$ and following transferring to HL were measured.

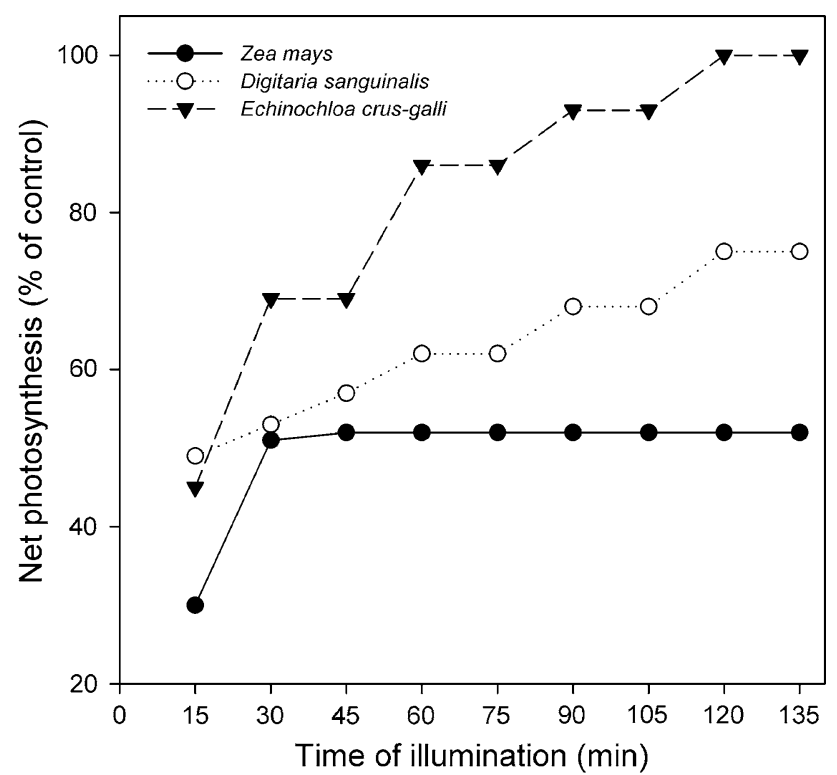

Fig. 1 Photosynthesis rates of detached leaves of Zea mays, Digitaria sanguinalis, and Echinochloa crus-galli plants growing in moderate light (ML) and after transferring from ML to high light (HL) for $1 \mathrm{~h}$. Photosynthesis was measured during $2 \mathrm{~h}$ of recovery after HL treatment and is expressed as a percentage of the control value (in $\mu \mathrm{mol} \mathrm{CO}_{2} \mathrm{~m}^{-2} \mathrm{~s}^{-1}$ ): Z. mays $13.22 \pm 0.62 ;$ E. crus-galli $23.02 \pm 0.64 ;$ D. sanguinalis $19.9 \pm 0.96$
Figure 1 shows the changes in the net photosynthesis $(\mathrm{Pn})$ rate observed during a short-term $(2 \mathrm{~h})$ period after the NADP-ME plants were treated with high light intensity. Before HL treatment, the control leaves of $D$. sanguinalis and E. crus-galli showed higher photosynthesis rate of 50 and $75 \%$, respectively, compared to Z. mays. After high light treatment, the photosynthesis rate in maize leaves decreased by about $70 \%$ compared to control leaves, and after a slight increase in light, the rate remained unchanged during the recovery period, reaching $50 \%$ of control value after 2 h. In E. crus-galli leaves, Pn rate decreased after photoinhibition by $55 \%$ and returned to the control level during the recovery period. In case of D. sanguinalis, Pn rate decreased by about $50 \%$ during photoinhibition, and after $2 \mathrm{~h}$ of recovery the rate was about $25 \%$ lower compared to the control leaves. The data obtained show that among the selected species, E. crus-galli was found to be the most resistant plant to photoinhibition.

The respiration rates of the NADP-ME species during growth conditions (ML) and following photoinhibition are shown in Fig. 2. Although the rate of Pn (Fig. 1) in $D$. sanguinalis was slightly lower than that in the E. crus-galli leaves, $\mathrm{CO}_{2}$ released during dark respiration following photosynthesis $\left(R_{1}\right)$ was different. E. crus-galli leaves showed a greater (about $100 \%$ ) increase in the rate of $R_{1}$

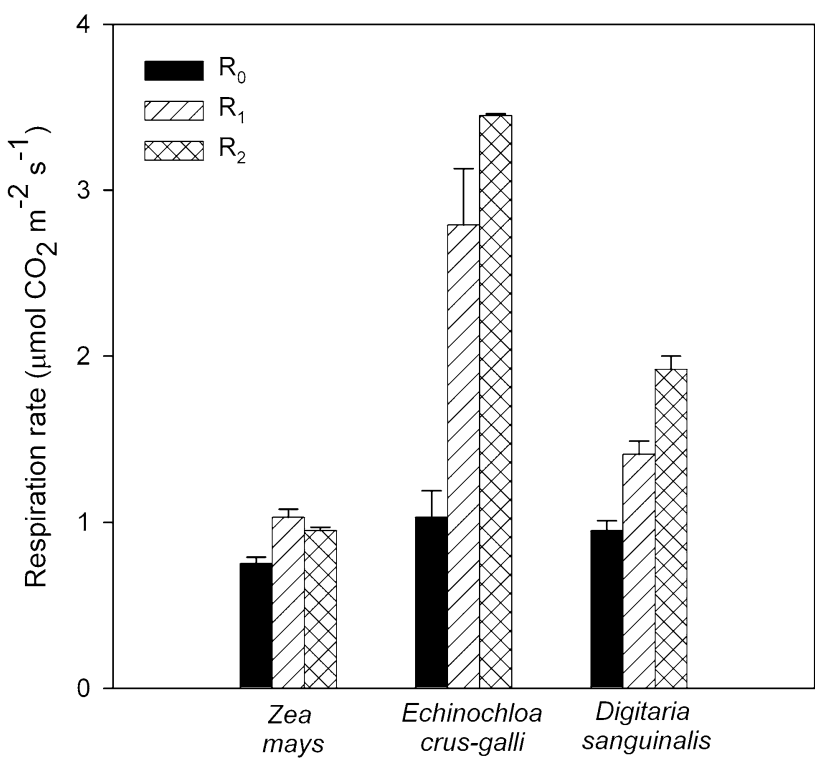

Fig. 2 Respiration rates of detached leaves of Zea mays, Echinochloa crus-galli, and Digitaria sanguinalis. $R_{0}$, respiration rate before photosynthesis was determined in leaves adapted to darkness for $10 \mathrm{~h}$. Then, the leaves were exposed to light $\left(400 \mu \mathrm{mol}\right.$ photons $\left.\mathrm{m}^{-2} \mathrm{~s}^{-1}\right)$ and photosynthesis (Pn) was measured. The respiration following photosynthesis $\left(R_{1}\right)$ was determined after 2-3 min of darkness, which represents the light-enhanced dark respiration (LEDR) of plants from growth condition (ML); $R_{2}$, respiration measured $2 \mathrm{~h}$ after photoinhibitory light treatment $\left(1600 \mu \mathrm{mol}\right.$ photons $\left.\mathrm{m}^{-2} \mathrm{~s}^{-1}\right)$. Values are the means of 4-5 separate experiments $\pm \mathrm{SE}$ 
compared to $D$. sanguinalis leaves and about 2.7-fold higher compared to maize, although the respiration before illumination $\left(R_{0}\right)$ has been comparable for $D$. sanguinalis and E. crus-galli, and it was higher by about $25 \%$ than that in maize. When the plants were transferred to HL, the respiration rate after $2 \mathrm{~h}$ of recovery after $\mathrm{HL}\left(R_{2}\right)$ increased by about 24 and $36 \%$ for E. crus-galli and $D$. sanguinalis, respectively. $R_{2}$ in $Z$. mays was on the same level as after photosynthesis in ML. The photochemical efficiency of PSII $(F \mathrm{v} / F \mathrm{~m})$ in the leaves of investigated NADP-ME plants (Table 1) was close to 0.8 in growth conditions, indicating that PSII is functional.

The $F \mathrm{v} / F \mathrm{~m}$ ratio is used for monitoring the in vivo effect of stress because it is linearly correlated with the quantum yield of light-limited $\mathrm{O}_{2}$ evolution. The $F \mathrm{v} / F \mathrm{~m}$ ratio measured after $1 \mathrm{~h}$ of photoinhibitory light treatment was dependent on the species, and it was lowest for maize (67\% of the control value). In case of E. crus-galli and $D$. sanguinalis leaves, it decreased by about 8 and 19\%, respectively (Table 1). Photochemical fluorescence quenching (qP) in the leaves of E. crus-galli, D.sanguinalis, and Z. mays grown under moderate light (ML) was similar when light intensity treatment was $400 \mu \mathrm{mol}$ photons $\mathrm{m}^{-2} \mathrm{~s}^{-1}$, whereas at $1020 \mu \mathrm{mol}$ photons $\mathrm{m}^{-2} \mathrm{~s}^{-1}$, qP declined by about 55 and $35 \%$ in Z. mays and D. sanguinalis and slightly in E. crus-galli (Fig. 3). After photoinhibitory light treatment, maximal reduction in $\mathrm{qP}$ was observed in maize leaves at PPFD of 400 and $1020 \mu \mathrm{mol}$ photons $\mathrm{m}^{-2} \mathrm{~s}^{-1}$. High light in E. crus-galli resulted in a slight decrease in $\mathrm{qP}$ values in both PPFD treatments. In case of $D$. sanguinalis leaves, the inhibitory effect of $\mathrm{HL}$ treatment on $\mathrm{qP}$ was higher compared to E. crus-galli leaves. In these plants, thermal dissipation of excitation energy, as expressed by non-photochemical fluorescence quenching of chlorophyll (NPQ), increased after HL treatment in all investigated species. A highest increase was observed for maize leaves at $1020 \mu \mathrm{mol}$ photons $\mathrm{m}^{-2} \mathrm{~s}^{-1}$ and it was about two times higher compared to $400 \mu \mathrm{mol}$ photons $\mathrm{m}^{-2} \mathrm{~s}^{-1}$. In the same conditions, for $E$. crus-galli, the NPQ was very similar after HL treatment at 400 and $1020 \mu \mathrm{mol}$ photons $\mathrm{m}^{-2} \mathrm{~s}^{-1}$, but for $D$. sanguinalis, the NPQ value was lowest at $400 \mu \mathrm{mol}$ photons $\mathrm{m}^{-2} \mathrm{~s}^{-1}$.

Light response curves have provided detailed information on the electron transport capacity and limitation of PSII. PAM fluorometry was complemented by other methods, in which photosynthesis and respiration rates were measured. ETR was higher in the plants grown under ML than after HL treatment in the leaves of all investigated species. Significant rise of the electron transport rate (Fig. $4 \mathrm{a}-\mathrm{c}$ ) was observed at the lower intensities of the light curve (up to about $200 \mu \mathrm{mol}$ photons $\mathrm{m}^{-2} \mathrm{~s}^{-1}$ ) and ETR was similar for ML and HL-treated species. In higher
Table 1 Effects of photoinhibitory light on the maximal efficiency of PSII phytochemistry $(F \mathrm{v} / F \mathrm{~m})$ in the dark-adapted leaves of Echinochloa crus-galli, Digitaria sanguinalis, and Zea mays in growth light conditions (ML) and after transferring leaves for $1 \mathrm{~h}$ to high light $(\mathrm{ML} \rightarrow \mathrm{HL})$

\begin{tabular}{lll}
\hline & \multicolumn{2}{l}{$/ F \mathrm{~m}$} \\
\cline { 2 - 3 } & $\mathrm{ML}$ & $\mathrm{ML} \rightarrow \mathrm{HL}$ \\
\hline Zea mays & $0.79 \pm 0.004$ & $0.53 \pm 0.038$ \\
Digitaria sanguinalis & $0.80 \pm 0.010$ & $0.65 \pm 0.004$ \\
Echinochloa crus-galli & $0.81 \pm 0.007$ & $0.75 \pm 0.016$ \\
\hline
\end{tabular}

Data are mean \pm SD of ten independent experiments

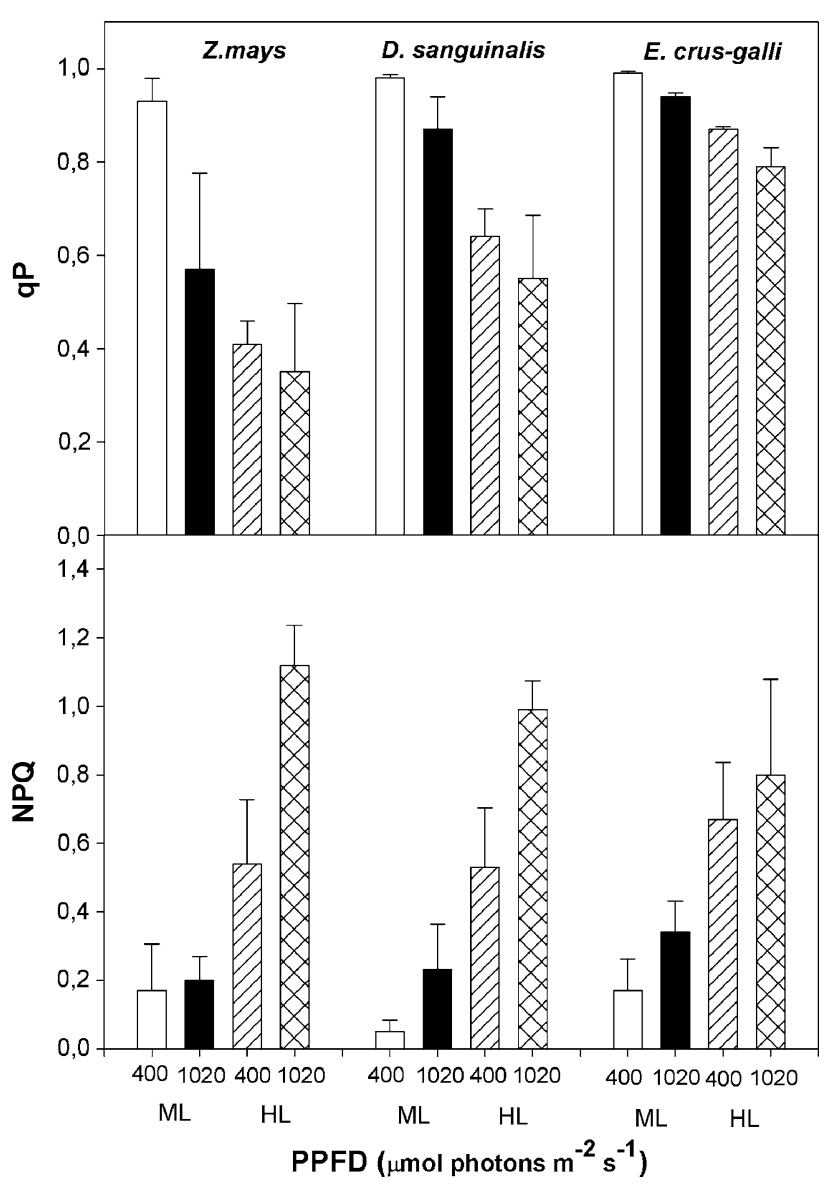

Fig. 3 Responses of photosystem II photochemical (qP) and nonphotochemical quenching coefficient (NPQ) to the actinic radiation (PPFD) of 400 and $1020 \mu \mathrm{mol}$ photons $\mathrm{m}^{-2} \mathrm{~s}^{-1}$ in Echinochloa crusgalli, Digitaria sanguinalis, and Zea mays leaves of plants grown in ML and after treatment for $1 \mathrm{~h}$ with high light intensity (HL, 1600 $\mu \mathrm{mol}$ photons $\mathrm{m}^{-2} \mathrm{~s}^{-1}$ ). Data are means \pm SE of 5-8 independent experiments

light intensities (above $540 \mu \mathrm{mol}$ photons $\mathrm{m}^{-2} \mathrm{~s}^{-1}$ ), ETR did not increase significantly for all plants, but there were differences between species, as well as for the ML and the HL-treated leaves. The highest ETR was observed for $E$. crus-galli and it was similar in both ML and HL-treated 


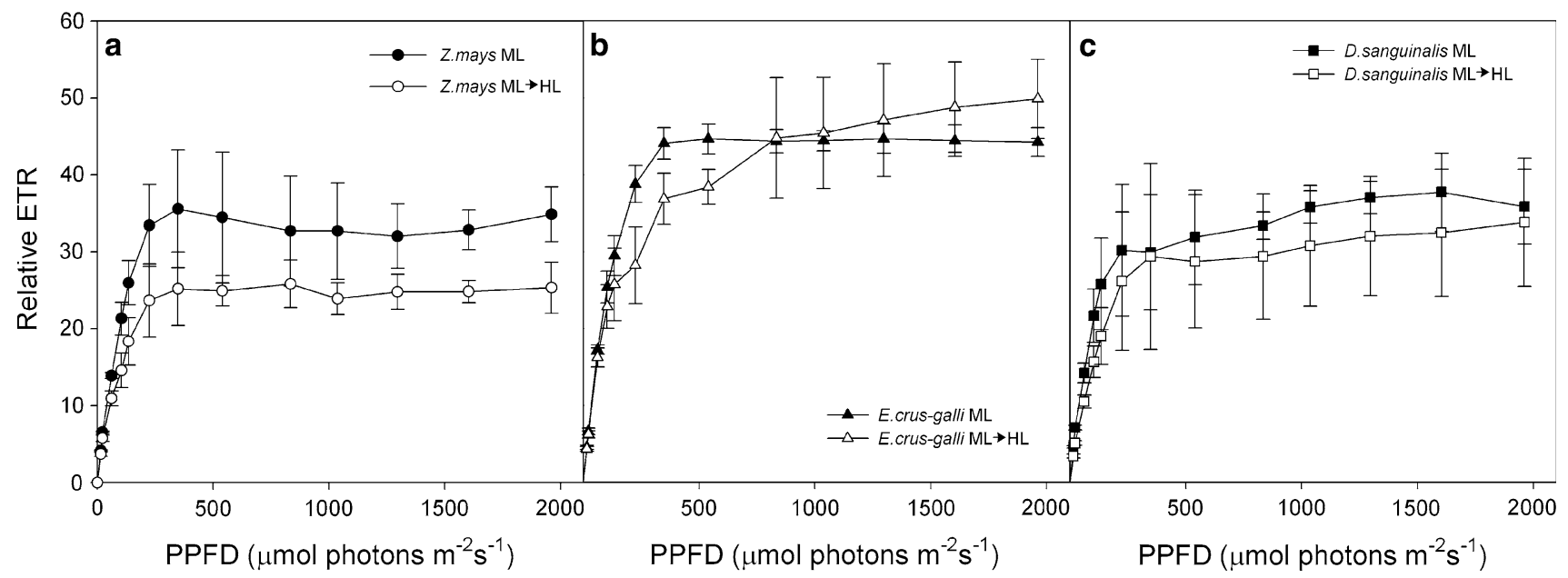

Fig. 4 The typical courses of relative electron transport rate (ETR) of Zea mays (a) Echinochloa crus-galli (b) and Digitaria sanguinalis (c) leaves of plants grown in ML and after treatment for $1 \mathrm{~h}$ with high

leaves. In Z. mays the ETR, after HL treatment, decreased by about $27 \%$ at the light intensity range between 500 and $1961 \mu \mathrm{mol}$ photons $\mathrm{m}^{-2} \mathrm{~s}^{-1}$, as compared with the ML, whereas in $D$. sanguinalis the HL inhibited ETR only slightly. The ETR after HL treatment was higher in E. crusgalli and then in D. sanguinalis and Z. mays by about $28 \%$ and $46 \%$, respectively. The decrease in rates of ETR at high irradiances for Z. mays may occur due to the inhibition of $\mathrm{CO}_{2}$ assimilation in this plant. On the other hand, the increasing rates of ETR in E. crus-galli at $>540 \mu \mathrm{mol}$ photons $\mathrm{m}^{-2} \mathrm{~s}^{-1}$ may be due to a better adaptation of the BS cells to $\mathrm{CO}_{2}$ fixation.

\section{Effect of light treatment on the carotenoids composition in the $M$ and BS thylakoids}

The pigment composition in the E. crus-galli, D. sanguinalis, and Z. mays $\mathrm{M}$ and $\mathrm{BS}$ thylakoids isolated from the leaves of control plants (ML) and after $1 \mathrm{~h}$ of photoinhibitory light treatment (ML $\rightarrow \mathrm{HL}$ ) is shown in Table 2. The amount of photoconvertible $\mathrm{V}$, expressed as a percentage of the $\mathrm{V}+\mathrm{A}+\mathrm{Z}$ pool in both $\mathrm{M}$ and $\mathrm{BS}$ thylakoids, isolated from the leaves of all investigated species after HL $\left(1600 \mu \mathrm{mol}\right.$ photons $\left.\mathrm{m}^{-2} \mathrm{~s}^{-1}\right)$ treatment, displayed a similar pool of photoconvertible V. Usually, the sun-exposed leaves displayed higher photoconvertible $\mathrm{V}$ than shade leaves, similarly as in the $\mathrm{C} 3$ leaves compared to the C4 leaves. Similar levels of photoconvertible $\mathrm{V}$ did not correlate with the corresponding differences obtained due to the level of NPQ (Fig. 3). However, for $E$. crus-galli and $D$. sanguinalis, the differences in the levels of $\mathrm{Z}+\mathrm{A} / \mathrm{Chl} a$ under ML and after HL correlated well with the level of NPQ. The $\mathrm{Z}+\mathrm{A}$ content increased after HL treatment significantly with one exception being the $D$. light intensity (ML $\rightarrow \mathrm{HL}$ ). ETR was measured as function of irradiance. The duration of irradiance at each level of actinic light was set to $60 \mathrm{~s}$

sanquinalis $\mathrm{BS}$ thylakoids, where exposure to $\mathrm{ML}$ and $\mathrm{HL}$ treatment yielded similar levels of $\mathrm{Z}+\mathrm{A}$. The total carotenoid contents (expressed on the basis of $\mathrm{Chl} a$ ) were very similar in $\mathrm{M}$ and $\mathrm{BS}$ thylakoids for all species, with a small noticeable decrease in both $\mathrm{M}$ and BS thylakoids of D. sanquinalis and Z. mays compared to E. crus-galli (about 20\%).

\section{PSII and PSI activities}

PSII and PSI activities were measured in M and BS thylakoids isolated from the leaves of plants grown under ML and after transferring to HL (Table 3). During growth, an influence of light intensity on the activity of both photosystems in the investigated plants was observed. PSII in BS chloroplasts was less active than that in $\mathrm{M}$ chloroplasts. Some previous reports demonstrated that PSII was not active in BS chloroplast of maize or had low activity, whereas in E. crus-galli and D. sanguinalis it was about two times higher than that in maize. In M thylakoids, PSII activity was lower in $E$. crus-galli and D. sanguinalis as compared to maize, about 57 and $40 \%$, respectively. Photoinhibitory light decrease of PSII activity reached about $50 \%$ in maize, whereas in $E$. crus-galli and D. sanguinalis it was only slightly diminished. In BS chloroplasts, HL treatment had a slight effect on PSII activity. Data of PSI and II activity measurements demonstrated that similar growth light conditions and inhibitory light induced various changes in $\mathrm{M}$ and BS chloroplasts of the investigated NADP-ME type C4 species. Large differences we observed between individual plants.

As expected, PSI activity was highest in maize BS chloroplasts and it was about 1.5 -fold higher than that in $E$. 
Table 2 Total carotenoids (lutein, neoxanthin, B-carotene, violaxanthin $(\mathrm{V})$, antheraxanthin (A), zeaxanthin (Z)) content; photoconvertible violoxanthin $(\mathrm{V})$ and $\mathrm{Z}+\mathrm{A}$ content in Echinochloa crus-galli,
Digitaria sanguinalis and Zea mays $\mathrm{M}$ and BS thylakoids isolated from the leaves of control plants (ML) and after $1 \mathrm{~h}$ of photoinhibitory light treatment $(\mathrm{ML} \rightarrow \mathrm{HL})$

\begin{tabular}{|c|c|c|c|c|c|c|}
\hline \multirow[t]{2}{*}{ Parameters } & \multicolumn{2}{|l|}{ Zea mays } & \multicolumn{2}{|c|}{ Digitaria sanguinalis } & \multicolumn{2}{|c|}{ Echinochloa crus-galli } \\
\hline & M & BS & M & BS & M & BS \\
\hline \multicolumn{7}{|l|}{ Total carotenoids (mol/100 mol Chl $a$ ) } \\
\hline ML & $27.4 \pm 0.63$ & $25.1 \pm 0.84$ & $24.9 \pm 2.15$ & $29.6 \pm 0.56$ & $33.6 \pm 1.56$ & $33.5 \pm 1.41$ \\
\hline $\mathrm{ML} \rightarrow \mathrm{HL}$ & $28.0 \pm 1.38$ & $24.7 \pm 1.38$ & $26.3 \pm 1.84$ & $25.3 \pm 1.89$ & $30.9 \pm 1.77$ & $34.2 \pm 0.48$ \\
\hline \multicolumn{7}{|l|}{$\mathrm{Z}+\mathrm{A}(\mathrm{mol} / 100 \mathrm{~mol} \mathrm{Chl} a)$} \\
\hline ML & $0.8 \pm 0.14$ & $0.7 \pm 0.07$ & $1.1 \pm 0.10$ & $1.3 \pm 0.15$ & $0.8 \pm 0.10$ & $1.3 \pm 0.21$ \\
\hline $\mathrm{ML} \rightarrow \mathrm{HL}$ & $2.8 \pm 0.52$ & $2.2 \pm 0.39$ & $2.0 \pm 0.21$ & $1.3 \pm 0.13$ & $2.8 \pm 0.37$ & $3.6 \pm 0.32$ \\
\hline Photoconvertible $\mathrm{V}(\%$ of $\mathrm{V}+\mathrm{A}+\mathrm{Z}$ ) after $\mathrm{HL}$ & 60.0 & 63.4 & 64.3 & 71.0 & 60.1 & 57.9 \\
\hline
\end{tabular}

Photoconvertible $\mathrm{V}$ is expressed on the basis of the $\mathrm{V}+\mathrm{A}+\mathrm{Z}$ pool. The data represent mean values $\pm \mathrm{SD}$ obtained from 3 different measurements of one sample from a typical experiment

Table 3 PSI and PSII electron transport activity in isolated mesophyll (M) and bundle sheath (BS) thylakoids of Echinochloa crusgalli, Digitaria sanguinalis, and Zea mays chloroplasts from control plants $\left(200 \mu \mathrm{mol}\right.$ photons $\left.\mathrm{m}^{-2} \mathrm{~s}^{-1}\right)$ and then transferred to high light (HL) for $1 \mathrm{~h}\left(1600 \mu \mathrm{mol}\right.$ photons $\left.\mathrm{m}^{-2} \mathrm{~s}^{-1}\right)$

\begin{tabular}{|c|c|c|c|c|c|c|c|c|}
\hline \multirow[t]{3}{*}{ Light intensity ( $\mu \mathrm{mol}$ photons $\mathrm{m}^{-2} \mathrm{~s}^{-1}$ ) } & \multicolumn{4}{|c|}{ PSII activity ( $\mu$ mol DCPIP $\mathrm{mg}^{-1} \mathrm{Chl} \mathrm{h}^{-1}$ ) } & \multicolumn{4}{|c|}{ PSI activity $\left(\mu \mathrm{mol} \mathrm{O} \mathrm{O}_{2} \mathrm{mg}^{-1} \mathrm{Chl} \mathrm{h}^{-1}\right)$} \\
\hline & \multicolumn{2}{|l|}{200} & \multicolumn{2}{|l|}{1600} & \multicolumn{2}{|l|}{200} & \multicolumn{2}{|l|}{1600} \\
\hline & M & BS & M & BS & M & $\mathrm{BS}$ & M & BS \\
\hline Zea mays & $89 \pm 1$ & $15 \pm 2$ & $47 \pm 1$ & $10 \pm 1$ & $296 \pm 1$ & $1020 \pm 9$ & $156 \pm 2$ & $565 \pm 3$ \\
\hline Digitaria sanguinalis & $40 \pm 1$ & $32 \pm 3$ & $37 \pm 1$ & $25 \pm 9$ & $284 \pm 6$ & $657 \pm 1$ & $176 \pm 1$ & $407 \pm 4$ \\
\hline Echinochloa crus-galli & $57 \pm 2$ & $30 \pm 7$ & $49 \pm 4$ & $22 \pm 9$ & $189 \pm 2$ & $671 \pm 2$ & $156 \pm 9$ & $429 \pm 5$ \\
\hline
\end{tabular}

Details are given in Materials and methods. The electron transport activities of PSI were measured polarographically at $25{ }^{\circ} \mathrm{C}$. Chloroplast equivalents of $30 \mu \mathrm{g} \mathrm{mL}^{-1}(\mathrm{M})$ and $10 \mu \mathrm{g} \mathrm{mL}^{-1}$ (BS) of chlorophyll were used for PSI measurements, chloroplast equivalents of $20 \mu \mathrm{g} \mathrm{mL} \mathrm{mL}^{-1}$ of chlorophyll were used for PSII measurements. DCPIP was $0.1 \mathrm{mM}$. Values are mean \pm SD of three independent experiments for PSI, means of 4-5 separate experiments \pm SE (three replicates each) for PSII

crus-galli and D. sanguinalis chloroplasts. The PSI activity was approximately threefold higher in BS chloroplasts compared to $\mathrm{M}$ chloroplasts in maize grown in similar conditions as E. crus-galli. The PSI activity in BS chloroplasts of $D$. sanguinalis was 2.3 times higher than that in M chloroplasts. High light treatment decreased PSI activity in both types of maize chloroplasts by about $50 \%$, in D. sanguinalis by about $40 \%$, whereas in E. crus-galli by about 18 and $36 \%$ in M and BS chloroplasts, respectively, compared with the control chloroplasts (from plants grown under ML conditions).

The ATP/ADP ratio in the leaves of NADP-ME plants in darkness, growth conditions (ML) and after photoinhibition is shown in Table 4. The ATP/ADP ratio differed between light conditions and was highest in the ML for all three species. E. crus-galli leaves had also the highest observable values of ATP/ADP ratio. The ATP/ADP ratio dropped by at least 50-60\% in the dark, as compared with growth conditions (ML) and it was also highest in E. crus-
Table 4 Effect of photoinhibition on the ATP/ADP ratio in the leaves of three selected species of NADP-ME grasses

\begin{tabular}{llll}
\hline & ATP/ADP & \\
\cline { 2 - 4 } & Darkness & ML & ML $\rightarrow$ HL \\
\hline Zea mays & 1.5 & 2.5 & 2.1 \\
Digitaria sanguinalis & 1.2 & 2.3 & 1.8 \\
Echinochloa crus-galli & 2.2 & 4.0 & 3.3 \\
\hline
\end{tabular}

Leaves were harvested from plants grown at $200 \mu \mathrm{mol}$ photons $\mathrm{m}^{-2} \mathrm{~s}^{-1}$ (ML) and then transferred to high light (HL, $1600 \mu \mathrm{mol}$ photons $\mathrm{m}^{-2} \mathrm{~s}^{-1}$ ) for $1 \mathrm{~h}$ as well as after a dark period $(10 \mathrm{~h})$

galli, in which dark respiration was highest (Fig. 2). Photoinhibitory light (ML $\rightarrow \mathrm{HL}$ ) caused the ATP/ADP ratio to decrease in leaves of all investigated species by about $16-20 \%$ as compared to ML. It was achieved by lower photosynthetic activity and, thus, lower respiration rate in these conditions (Figs. 1, 2). 


\section{PSII protein phosphorylation after photoinhibition}

Modulations of PSII protein phosphorylation under photoinhibitory conditions in $\mathrm{M}$ and $\mathrm{BS}$ thylakoids isolated from control ( $2 \mathrm{~h}$ of ML illumination after night) and $1 \mathrm{~h}$ HL-treated leaves of NADP-ME grasses are shown in Fig. 5. Typically, low light conditions trigger only LHCII proteins phosphorylation, whereas phosphorylation of D1 protein is irradiance dependent. If similar light conditions differently influence protein phosphorylation in the investigated thylakoids, then we can assume that all investigated chloroplasts have different phosphorylation status. High light treatment of plant leaves increased the phosphorylation level of D1 in both M and BS thylakoids, as compared to ML controls (Fig. 5). The phosphorylation of D1 protein in $\mathrm{M}$ and BS thylakoids of E. crus-galli was higher than that in maize or in both types of thylakoids of $D$. sanguinalis. However, the phosphorylation of LHCII was higher in BS thylakoids than that in M thylakoids for all investigated plants, which may suggest that BS chloroplasts were exposed to lower light intensity compared to $\mathrm{M}$ chloroplasts, hence a low-light exposure phosphorylation pattern of LHCII was observed. In M chloroplasts, LHCII proteins were phosphorylated in ML and dephosphorylated in HL, suggesting light overexposure. These results indicate that differences in phosphorylation of PSII proteins might be related to light intensity that is effectively reaching the chloroplasts (M or BS) and/or their redox status in different species. Changes in phosphorylation of PSII proteins in maize $\mathrm{M}$ and BS thylakoids exposed to different light quality were observed already earlier (Zienkiewicz et al. 2015). These experiments clearly demonstrate that the same light conditions have different effect on phosphorylation of D1 and LHCII proteins in M and BS thylakoids among investigated plants, grown in the same light conditions. After HL treatment, the level of D1 protein in M and BS thylakoids remained at a similar level, despite elevated NPQ and lower PSII activity levels as compared to plants grown in ML.

\section{Abundance of $M$ protein complexes in response to photoinhibitory light}

To compare the abundance of protein complexes during the high light stress in thylakoids of NADP-ME species, we employed blue-native (BN) electrophoresis. A typical pattern of the thylakoid membrane protein complexes is shown in Fig. 6. Thylakoids were isolated from control and HL-treated NADP-ME C4 plants. Under these conditions, 11 main protein bands, corresponding to thylakoid membrane complexes, were identified. The electrophoresis showed that the super-organization of thylakoid membrane proteins was not affected by short-term treatment with HL. The PSII and PSI complexes, together with various combinations of LHC, were resolved in 6 bands in ML and 5 bands in HL, and the remaining complexes did not show any differences between ML and HL. Bands representing the trimeric forms of the light-harvesting complex of PSII (LHCII) did not change significantly. Furthermore, no significant variations of the bands containing the cytochrome $b_{6} f$ and the ATP synthase complexes were observed. In this assay, the protein profiles obtained for control and HL-treated leaves were clearly similar. These data demonstrate that HL does not disturb the organization of thylakoid complexes. The preservation of the complexes cannot explain the observed decrease of photosystems
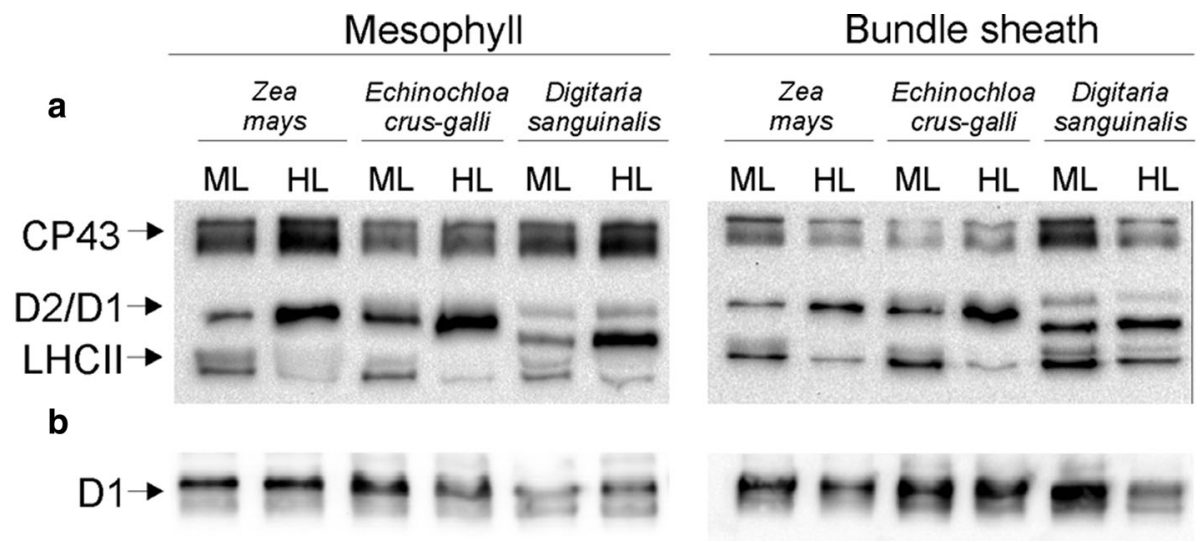

Fig. 5 PSII protein phosphorylation in mesophyll and bundle sheath thylakoids isolated from the leaves of Zea mays, Digitaria sanguinalis, and Echinochloa crus-galli. The leaf samples were collected $2 \mathrm{~h}$ after growth light (ML) was turned on, and after that leaves were shifted for $1 \mathrm{~h}$ to high light (HL, $1600 \mu \mathrm{mol}$ photons $\mathrm{m}^{-2} \mathrm{~s}^{-1}$ ) from ML (a). Gel wells were loaded with $1.5 \mu \mathrm{g}$ of $\mathrm{Chl}$ equivalents of the isolated thylakoids. Phosphorylated proteins were detected with anti-
PThr antibody. The positions of detected phosphoproteins are indicated on the left side. The level of D1 protein in thylakoids was confirmed using D1 protein-specific antibody (Agrisera) (b). Thylakoid proteins $(1.0 \mu \mathrm{g} \mathrm{Chl})$ were separated by urea SDS-PAGE and immunodetected. The results shown are representative of those obtained in at least three independent experiments. Thylakoids were isolated in the presence of $10 \mathrm{mM} \mathrm{NaF}$ 


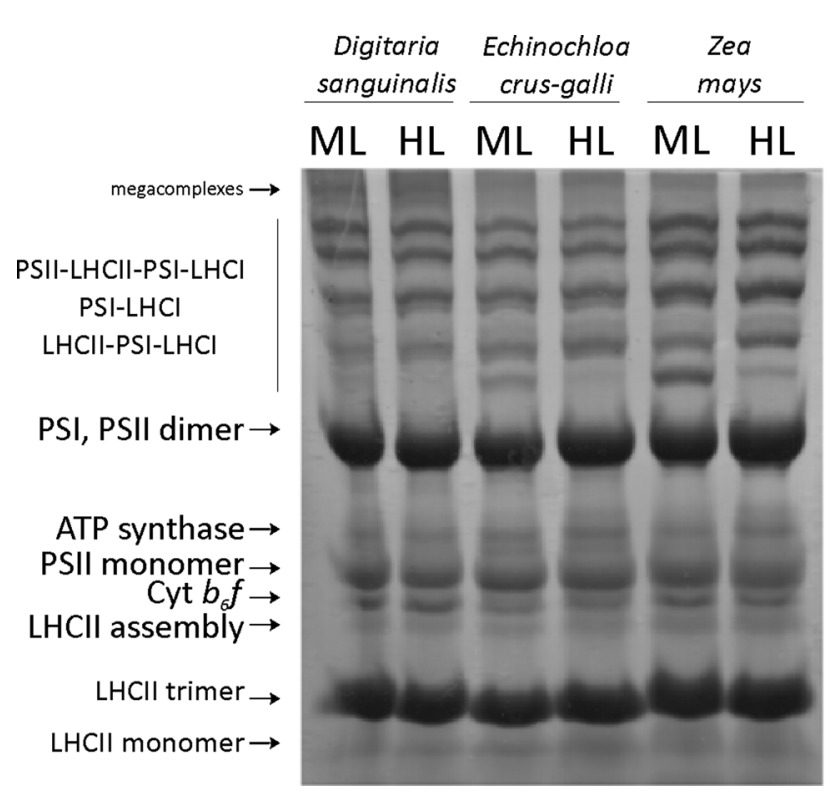

Fig. 6 Blue native (BN)-PAGE. The composition of protein complexes in thylakoids isolated from mesophyll (M) chloroplasts of Digitaria sanguinalis, Echinochloa crus-galli, and Zea mays. Thylakoids were isolated from the leaves of plants grown at $200 \mu \mathrm{mol}$ photons $\mathrm{m}^{-2} \mathrm{~s}^{-1}$ (ML) and from the leaves transferred to $\mathrm{HL}$ $\left(1600 \mu \mathrm{mol}\right.$ photons $\left.\mathrm{m}^{-2} \mathrm{~s}^{-1}\right)$ for $1 \mathrm{~h}$. Equivalents of $45 \mu \mathrm{g}$ of $\mathrm{Chl}$ were loaded onto each lane. The identification of the complexes was done as described before (Mekala et al. 2015)

activity upon increase of light intensity. The disappearance of the LHCII-PSI-LHCI complex indicates changing dynamics of the thylakoid complexes during short-term light changes. Interestingly, we did not observe any differences between $\mathrm{M}$ thylakoids of the investigated species.

\section{Effect of $\mathrm{HL}$ treatment on $\mathrm{H}_{2} \mathrm{O}_{2}$ and MDA content}

The HL treatment affected the content of hydrogen peroxide $\left(\mathrm{H}_{2} \mathrm{O}_{2}\right)$ and malondialdehyde (MDA) in the leaves of investigated $\mathrm{C} 4$ species (Table 5). After HL treatment, the content of MDA increased about 38, 32, and $88 \%$ for $Z$. mays, E. crus-galli and D. sanguinalis leaves, respectively, as compared to controls (ML). The MDA content in control and HL-treated maize leaves was higher than that in $E$. crus-galli and D. sanguinalis leaves. The level of the $\mathrm{H}_{2} \mathrm{O}_{2}$ was higher in maize leaves than that of $D$. sanguinalis and E. crus-galli grown in ML, by about 70 and $76 \%$, respectively. The level of $\mathrm{H}_{2} \mathrm{O}_{2}$ in $\mathrm{ML}$ leaves was higher as compared to HL-treated leaves and it decreased by about $56 \%$ in maize and by about $23-25 \%$ in both E. crus-galli and $D$. sanguinalis leaves exposed to HL.

The APX activity was highest in E. crus-galli leaves and it did not change after HL stress (Table 6). In D. sanguinalis, APX activity was lowest in growth condition (ML) and increased twofold during high light treatment. In Z. mays leaves, APX activity decreased by about $30 \%$ after
Table 5 Effects of photoinhibitory light (HL, $1600 \mu \mathrm{mol} \mathrm{m} \mathrm{m}^{-2} \mathrm{~s}^{-1}$ ) on $\mathrm{H}_{2} \mathrm{O}_{2}$ generation and lipid peroxidation measured as the malondialdehyde (MDA) content in the leaves of Zea mays, Digitaria sanguinalis, and Echinochloa crus-galli plants grown at $200 \mu \mathrm{mol}$ photons $\mathrm{m}^{-2} \mathrm{~s}^{-1}$ (ML) and transferred to high light (ML $\rightarrow \mathrm{HL}$ ) for $1 \mathrm{~h}$

\begin{tabular}{|c|c|c|c|c|}
\hline & \multicolumn{2}{|l|}{ ML } & \multicolumn{2}{|c|}{$\mathrm{ML} \rightarrow \mathrm{HL}$} \\
\hline & \multicolumn{4}{|c|}{$\left(\mu \mathrm{mol} \mathrm{g}{ }^{-1} F \mathrm{w}\right)$} \\
\hline & $\mathrm{H}_{2} \mathrm{O}_{2}$ & MDA & $\mathrm{H}_{2} \mathrm{O}_{2}$ & MDA \\
\hline Zea mays & 0.93 & 11.9 & 0.52 & 16.5 \\
\hline Digitaria sanguinalis & 0.29 & 7.4 & 0.22 & 13.9 \\
\hline Echinochloa crus-galli & 0.22 & 8.5 & 0.17 & 11.2 \\
\hline
\end{tabular}

HL treatment. SOD activity increased after HL treatment in D. sanguinalis (about twofold) and in E. crus-galli (25\%), whereas in maize it was not changed.

\section{Discussion}

We have examined the effect of high light irradiation on photosynthesis, respiration and energetic status of leaves, and photochemical activities of mesophyll and bundle sheath thylakoids of the C4 NADP-ME species, in particular: Z. mays, E. crus-galli and D. sanguinalis. The light exposure variation in the environment is expected to alter the interaction between the functions of $\mathrm{C} 4$ plants chloroplasts due to the unequal distribution of excitation energy between M and BS chloroplasts (Tazoe et al. 2008). Little is known about the influence of light variation on the photochemical response of various species of NADP-ME C4 subtype. It also remains largely unknown, whether different mechanisms are required for adjustment of photosynthesis upon the induced changes in light quality and intensity in dependence on variation in the amounts of grana in BS chloroplasts. Ueno et al. (2005) have evaluated the granal index in BS chloroplasts of $\mathrm{C} 3$ and $\mathrm{C} 4$ grasses and ranked the degree of granal development in $Z$. mays, $D$. sanguinalis and in E. crus-galli, respectively, <3\%, 5-10\% and $15-25 \%$. Its probably reflects the BS chloroplasts differences in the availability of the reducing power, which limits for $\mathrm{CO}_{2}$ fixation. In this paper, we set out to investigate the influence of the short-term effect of HL stress on the function of $\mathrm{M}$ and $\mathrm{BS}$ chloroplasts of the selected three species grown under medium light intensity (ML). It is unknown whether these species show the same response to photoinhibitory light. We compared the responses of the leaves and thylakoids to photoinhibitory light treatment with those resulting from control growth conditions (ML). We addressed the questions why do the NADP-ME C4 species respond differently to high light and what is the reason for the apparent photosynthetic differences in these 
Table 6 Effects of photoinhibitory light (HL, $1600 \mu \mathrm{mol} \mathrm{m} \mathrm{m}^{-2} \mathrm{~s}^{-1}$ ) on APX and SOD activity in the leaves of Zea mays, Digitaria sanguinalis, and Echinochloa crus-galli plants growing in $200 \mu \mathrm{mol}$ photons $\mathrm{m}^{-2} \mathrm{~s}^{-1}$ (ML) and transferred to high light (ML $\rightarrow \mathrm{HL}$ ) for $1 \mathrm{~h}$

\begin{tabular}{|c|c|c|c|c|c|c|}
\hline \multirow[t]{2}{*}{ Parameters } & \multicolumn{2}{|l|}{ Zea mays } & \multicolumn{2}{|c|}{ Digitaria sanguinalis } & \multicolumn{2}{|c|}{ Echinochloa crus-galli } \\
\hline & ML & $\mathrm{ML} \rightarrow \mathrm{HL}$ & ML & $\mathrm{ML} \rightarrow \mathrm{HL}$ & ML & $\mathrm{ML} \rightarrow \mathrm{HL}$ \\
\hline APX $\left(\mu \mathrm{mol}\right.$ Asc $\min ^{-1} \mathrm{mg}^{-1}$ protein $)$ & $0.30 \pm 0.05$ & $0.21 \pm 0.04$ & $0.1 \pm 0.01$ & $0.2 \pm 0.02$ & $0.46 \pm 0.07$ & $0.48 \pm 0.08$ \\
\hline $\mathrm{SOD}\left(\mathrm{U} \mathrm{mg}^{-1}\right.$ protein $)$ & $9.80 \pm 1.1$ & $10.1 \pm 0.9$ & $2.1 \pm 0.4$ & $4.7 \pm 0.8$ & $5.9 \pm 0.4$ & $7.4 \pm 0.6$ \\
\hline
\end{tabular}

Data are mean $\pm \mathrm{SD}(n=3-5)$

plants? Is there a species-specific mechanism responsible for these effects?

Our results showed that the plants grown in identical light conditions responded differently to photoinhibitory light. The most resistant to photoinhibition was the weed plant $E$. crus-galli which developed a strategy, allowing to maintain a high photosynthetic activity while protecting the thylakoid proteins from degradation mainly by PSII protein phosphorylation (Fig. 5), high pool of carotenoids (Table 2), and high energization of the leaves (Table 4). The investigated $\mathrm{C} 4$ grasses have different granal index of the BS chloroplasts (Ueno et al. 2005). Taking into account that the chloroplast grana are the site where $\mathrm{O}_{2}$ is evolved due to PSII activity, the $\mathrm{O}_{2}$ and $\mathrm{CO}_{2}$ partial pressure values in the BS cells may differ between species. Greatly the reduced grana in BS chloroplasts correlate reasonably well with the differences in PSII activity (Table 3) and simultaneously reduced the BS chloroplasts production of reactive oxygen species (ROS) (Doulis et al. 1997). Also there are differences in the suberization of the BS cell walls. There is considerable heterogeneity in sheath cell development and suberin composition, both within and between grass taxa (Mertz and Brutnell 2014). It probably prevents the leakage of $\mathrm{CO}_{2}$ from these cells in a different way. In case of NADP-ME species, the decreased rate of grana formation in BS, and increased malate transport together with decarboxylation, can provide compensatory reducing power (Hatch 1987). Thus, the amount of grana in BS is a specialized feature whose increased demands are satisfied by co-operation between the two cell types and induction of metabolic changes or the changes in the transport of metabolites. The measurements of photosynthesis and respiration rates (Figs. 1,2) show lower $\mathrm{CO}_{2}$ exchange rate in the leaves of $Z$. mays compared to $D$. sanguinalis and $E$. crus-galli, which is possibly caused by the limitation of Calvin cycle reactions in maize. In Z. mays, the rate of photosynthesis after HL treatment was significantly lower than that of D. sanguinalis and E. crus-galli. We think that, in maize $\mathrm{BS}$ cells, a more rapid release of $\mathrm{CO}_{2}$ than fixation by the Calvin pathway could result from the limited reducing potential in the BS chloroplasts, which is likely to occur after a period of ML treatment. This may indicate
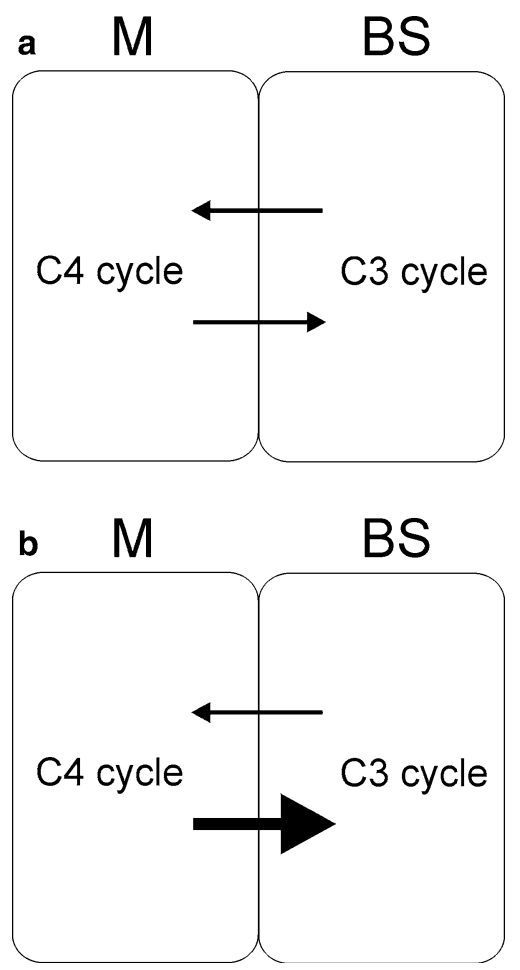

Fig. 7 Schematic representation of the metabolite transport between mesophyll (M) and bundle sheath (BS) cells in plants grown under moderate light (a) and treated for $1 \mathrm{~h}$ with high light (b)

that in BS cells of the investigated plants the assimilatory capacity differs and it is inadequate when the light transition is of short duration. We propose that the rate of C4cycle reactions, moving metabolites from $\mathrm{M}$ to BS cells, is faster during the short-term duration of the HL then in the ML and the Calvin cycle reactions can't utilize them (Fig. 7). This suggests that according to the capacity of the BS chloroplasts to produce $\mathrm{O}_{2}$ and the reducing power, the related differences may occur in the potential of photosynthesis in these grasses.

Previously, it was shown that maize BS cells have a relatively high conductance to $\mathrm{CO}_{2}$ which could result in $\mathrm{CO}_{2}$ level around Rubisco (Dai et al. 1995). Other $\mathrm{C} 4$ species also show differences in conductance to $\mathrm{CO}_{2}$ in $\mathrm{BS}$ cells (Brown and Byrd 1993). The observed changes might influence the $\mathrm{CO}_{2}$ assimilation rate. In E. crus-galli, the 
higher rate of photosynthesis and respiration correlated well with higher amount of ATP as shown in Table 4. The $\mathrm{CO}_{2}$ assimilation correlated with the electron transport rate (ETR), and the observed differences are found, for the investigated species, in both, the growth conditions (ML) and after treatment of leaves with the high light (ML $\rightarrow$ HL) (Fig. 4). Substantial differences in the ETR were found between $Z$. mays and E. crus-galli, indicating a severe limitation in the electron transport in the HL-treated maize leaves. Chlorophyll $a$ fluorescence at room temperature is widely used to probe the photosynthetic functions and regulations of plants in vivo (Schreiber 1983). Photochemical quenching $(\mathrm{qP})$ is generally thought to reflect the rate of electron transport and hence photosynthetic flux, whereas non-photochemical quenching (NPQ) reflects heat dissipation of the excitation energy in the antenna system (Baker 2008). In M of C4 plants, where Rubisco is absent, the $\mathrm{qP}$ reflects electron transport more accurately than that in C3 chloroplasts. Also, the lower level of PSII abundance in BS chloroplasts means that the whole leaf variable fluorescence emanates almost exclusively from the $M$ thylakoids, which simplifies the interpretation of the signal. The photochemical quenching (qP) (Fig. 3) in the leaves of E. crus-galli after HL treatment decreased slightly since the photosynthesis rate (Fig. 1) after photoinhibitory light treatment could rapidly reach values similar to the values of the control plants. Recovery of photosynthesis in $E$. crus-galli leaves observed after photoinhibition could be related to acclimation that reduces the influence of the excess light in thylakoids without a negative effect on the $\mathrm{CO}_{2}$ assimilation rate. The decrease in the $\mathrm{qP}$ in E. crusgalli leaves under HL correlates with the increased dissipation of non-radiative energy (NPQ) and with a higher pool of antheraxanthin and zeaxanthin $(A+Z)$ in the investigated plants. However, the total pool size of carotenoids and the proportion of the photoconvertible violaxanthin are found to be similar in all the investigated species (Table 2). Depending on the available light irradiation, plants have the possibility to adapt to high- or lowlight condition. They can switch their photosynthetic apparatus between light harvesting and excess energy dissipation. Many observations indicate that the interactions between chlorophylls and carotenoids seem to be crucial for the excess energy dissipation (Holleboom and Walla 2014). It is known that there are differences in the efficiencies of energy transfer between carotenoids and chlorophylls for different species as well as light-harvesting complexes, but the explanation of this phenomenon is not yet satisfactory (Ritz et al. 2000).

Changes in the NPQ among species are probably attributable to differences in photosynthetic capacity, and the observed lower values of the $\mathrm{qP}$ in $\mathrm{HL}$ cannot be explained only by increased heat dissipation. The increased
NPQ in different investigated species exposed either to ML or to HL may occur due to species-specific response of plants to light and also to other photochemical differences induced by $\mathrm{M}$ and $\mathrm{BS}$ thylakoid protein composition. Similarly, the amount of $\mathrm{Z}+\mathrm{A}$ (zeaxanthin + antheraxanthin) in the NADP-ME C4 species can confirm the observation that $\mathrm{Z}$ (zeaxanthin) is not a prerequisite for NPQ, because significant levels of NPQ may be induced in the absence of zeaxanthin (Noctor et al. 1991). Our results indicate that possible causal links between zeaxanthin and the NPQ are less obvious in C4 plants than expected. Further studies of this subject are need.

The phosphorylation of LHCII proteins is controlled by the redox state of the plastoquinone pool (Allen 2002). Modulation of light intensity provides a model system for studying the regulation of thylakoid membrane proteins phosphorylation in $\mathrm{M}$ and $\mathrm{BS}$ chloroplasts and in relation to its structure and function. The changes in the ATP/ADP ratio in leaves also indicate whether any modulation of PSII proteins phosphorylation occurs. For example, a high ATP/ADP ratio in E. crus-galli leaves in control conditions probably favors protein phosphorylation, in contrast to maize and D. sanguinalis (Table 4). However, exposure to $\mathrm{HL}$ resulted in a decreased ATP/ADP ratio by about $15-20 \%$ in all species, affecting the activity of key $\mathrm{C} 4$ enzymes (Nakamoto and Young 1990; Tazoe et al. 2008) and, in effect, the $\mathrm{CO}_{2}$ assimilation rates. In case of $E$. crus-galli leaves, upon changing photon irradiance from ML to HL, photosynthesis rate decreased and then returned to the control level during $2 \mathrm{~h}$ of recovery period (Fig. 1) indicating a high efficiency of the photosynthetic machinery.

It is by now relatively well documented that chloroplasts display a broad range of plasticity regarding the stacked and unstacked thylakoid formation as an adaptation to environmental changes (Maxwell et al. 1999). It was shown previously that there is a different resistance mechanism to various stress factors in $\mathrm{M}$ and $\mathrm{BS}$ chloroplasts. Particularly, in the $\mathrm{M}$ chloroplasts of maize, the photosynthetic output was inhibited as a result of the granal stacking damaged after $\mathrm{NaCl}$ treatment, while in the BS chloroplasts, it was increased (Hasan et al. 2006). Results similar to those of maize were obtained by Omoto et al. (2009) for other seven C4 NADP-ME species. The NADP-ME grasses are good model organisms to compare the responses to different stress factors, because of the two types of chloroplasts, mesophyll (rich in PSII) and bundle sheath (rich in PSI), with different redox statuses and ATP contents. Our results confirm that BS chloroplasts lacking grana are deficient in PSII, but they contain an active PSI. The high light stress does not affect the photochemical efficiency of PSII in E. crus-galli as much as in Z. mays, and only a small drop was observed in the measured $F \mathrm{v} / F \mathrm{~m}$ 
ratio (maximal efficiency of PSII) (about 10\%) (Table 1). These results are well in agreement with the observation showing that the PSII activity (Table 3) was not significantly affected by HL exposure of thylakoids isolated from both the E. crus-galli and D. sanguinalis BS chloroplasts, where the photoreduction of dichlorophenol-indophenol (DCPIP) rate remained unchanged. Contrary to that, HL stress had an inhibitory effect on the electron transport through PSII in BS thylakoids of Z. mays. The decreasing activity of PSII was probably related to damages occurring, due to stress, on the donor side of PSII. To investigate the possible effect of HL stress on the organization of the major protein complexes in the thylakoid membrane from $\mathrm{M}$ chloroplasts, we employed blue-native (BN) electrophoresis (Fig. 6). In this assay, the control (ML) protein profiles and the HL-treated leaves were clearly similar, which demonstrated that $1 \mathrm{~h}$ of $\mathrm{HL}$ does not disturb the organization of thylakoid complexes, although it has an inhibitory effect on the photosynthesis rate. This stands in agreement with the fluorescence measurements and PSII activities. The results showed that the short-term effect of HL irradiation causes a decrease in fluorescence, photochemical activity of PSII and PSI, as well as the energetic status of the leaves. However, this two-cell-type system allows to maintain a high photosynthetic activity. Probably, the crucial mechanism, which is involved in the metabolism and regulation/stabilization of protein structure in stress conditions, is a reversible protein phosphorylation. The regulation and physiological significance of phosphorylation/dephosphorylation in both chloroplasts of NADPME type $\mathrm{C} 4$ species are related to the supramolecular organization of the thylakoid membranes/complexes during photoinhibition.

High light significantly enhanced the phosphorylation of the D1 protein in both types of chloroplasts and induced dephosphorylation of LHCII (Fig. 5). We detected the highest phosphorylation level of the D1 protein in M and BS thylakoids of E. crus-galli, which suggests a better protection of PSII against photoinhibition compared to $D$. sanguinalis and Z. mays. It was found earlier that the phosphorylated form of D1 was resistant to degradation (Rintämaki et al. 1996). Moreover, the HL which induces photoinhibitory effects did not cause any changes in the total amount/content of D1protein (Fig. 5b) in all the examined species. These results correlate well with the photochemical activities. In addition, the different phosphorylation level of PSII proteins (Fig. 5a) and changes in the PSI-LHCII supercomplexes (Fig. 6) indicate different redox states not only in both types of chloroplast but also between investigated plants. Different phosphorylation of LHCII in M and BS chloroplasts and among the $\mathrm{C} 4$ species in $\mathrm{ML}$ and $\mathrm{HL}$ might be the mechanism by which the $\mathrm{C} 4$ plants regulate the distribution of excitation energy to both photosystems and maintain the proper function of photosynthetic machinery.

Chloroplasts are plant organelles that are most sensitive to various stress factors because they are the major sources of ROS production in plants cells (Asada 2006). Due to minimal activity of PSII in the BS chloroplasts of NADPME species, the ROS production is largely limited and much lower than that in the $\mathrm{M}$ chloroplasts. Hence, the $\mathrm{M}$ chloroplasts as compared to the BS are more sensitive to oxidative stresses induced by various factors (Foyer et al. 2002; Omoto et al. 2009). The two photosynthetic cell types of the NADP-ME species in accordance with its structure and function help in the efficient photosynthesis even during irradiation stress. To maintain continuously the $\mathrm{C} 4$ cycle, energy must be generated photochemically and the coordinated transport of metabolites must take place. Various mechanisms are involved in sustaining the homeostasis in leaves. High light stress has different effects on the rate of photosynthesis and respiration among the selected three species. The antioxidant system in all the species reacted differently after exposure to HL treatment (Tables 5, 6). Activities of superoxide dismutase (SOD) were found to be increased in the leaves of E. crus-galli and $D$. sanguinalis, whereas in maize they remained unchanged. The activity of ascorbate peroxidase (APX) increased in D. sanguinalis, decreased in maize, and remained unchanged in E. crus-galli. Malondialdehyde (MDA) levels increased in all plants and the $\mathrm{H}_{2} \mathrm{O}_{2}$ amount decreased after HL treatment. E. crus-galli showed a slight increase in the MDA content (Table 5) compared to $Z$. mays, which indicates that this might be due to the higher content of saturated fatty acids in its lipid membranes. It is, therefore, possible that another adaptation mechanism of the NADP-ME plants to stress conditions may proceed via variations in their fatty acid composition of the lipid membrane. The $\mathrm{H}_{2} \mathrm{O}_{2}$ plays a dual role in plants. At low concentrations, it acts as a secondary signaling molecule involved in the acclimatory signal triggering and raising a tolerance level to various stresses. On the other hand, $\mathrm{H}_{2} \mathrm{O}_{2}$ accumulation gives rise to membrane lipid peroxidation when sufficiently high concentrations are attained (Foyer and Noctor 2005). Our results indicated that the HL treatments did not induce oxidative stress, which was confirmed by the $\mathrm{H}_{2} \mathrm{O}_{2}$ and MDA levels in the leaves of $\mathrm{C} 4$ plants, and increased concentrations of MDA did not induce membrane damage. Likely, $\mathrm{H}_{2} \mathrm{O}_{2}$ that was generated was scavenged efficiently enough. The observed decrease in the photosynthesis rate of maize is likely related to changes in $\mathrm{M}$ chloroplasts due to differences in light saturation of both types of chloroplasts. The higher light intensity was permeating the $\mathrm{M}$ chloroplasts better than the BS chloroplasts, according to the light penetration profile (Zienkiewicz et al. 2015). Therefore, we are 
inclined to conclude that the differences in the reaction of NADP-ME species to HL treatment are due to the different photon absorption rate by chloroplasts, located in particular type of tissues.

We found that both types of leaves of E. crus-galli and D. sanguinalis grown under $\mathrm{ML}$ fixed and released $\mathrm{CO}_{2}$ before photosynthesis $\left(R_{0}\right)$ at a similar rate, whereas respiration after Pn $\left(R_{1}\right)$ was different. The leaves of E. crusgalli showed higher rate of $\mathrm{CO}_{2}$ evolution than $D$. sanguinalis (Fig. 2), suggesting that the increased level of $\mathrm{CO}_{2}$ evolution might be due to enhanced utilization of malate. Malate can be used, besides its role in photosynthesis, in mitochondrial respiration, providing a likely explanation for the high ATP/ADP ratio observed in E. crus-galli leaves. We conclude that high efficiency of PSII, higher adenylate pool and PSI and PSII activity after the HL treatment, as well as stronger phosphorylation status of PSII proteins can play a decisive role in granting a better resistance to photoinhibition in E. crus-galli compared to the other species. In E. crus-galli leaves, the pool size of the xanthophylls cycle components was slightly higher than for Z. mays and D. sanguinalis. The percentage of photoconvertible violaxanthin (V) was very similar among all the three species and also between the M and BS thylakoids. Additionally, the zeaxanthin and antheraxanthin $(\mathrm{Z}+\mathrm{A})$ content increased after the HL treatment in all the analyzed species. Thus, it seems that a reduced rate of $\mathrm{CO}_{2}$ assimilation in HL for maize leaves was likely not related to changes in the content of xanthophyll cycle pigments. Their levels were almost the same as in D. sanguinalis where Pn after the HL treatment was higher. The decreased PSII efficiency ( $F \mathrm{~V} / F \mathrm{~m}$ ratio) observed for maize leaves in HL could be related to the limitation of carbon supply in BS or qI quenching related to photoinhibition without damaging of D1 protein (Fig. 5b). The drastic decrease in $\mathrm{CO}_{2}$ uptake in maize leaves after exposure to HL treatment could be a simple effect of a high decrease in photosystems activity caused by photoinhibitory light. We also suggest that the adenylate pool found similar in all light conditions in maize and D. sanguinalis was not the major limiting factor for $\mathrm{CO}_{2}$ assimilation. It seems that in maize the $\mathrm{CO}_{2}$ uptake controls the PSII efficiency. The light intensity which penetrates into the leaves may control the level of phosphorylation of PSII proteins and thus photoinhibition. The differences in the PSI and PSII activity in chloroplasts of both cell types of $\mathrm{C} 4$ species indicate that these plants have different ratios of energy production in cyclic and noncyclic electron flow, stemming from different capacity to produce sufficient amounts of NADPH and ATP needed for fixing $\mathrm{CO}_{2}$.

Author contribution statement ER conceived this study. ER and MZ designed and evaluated the experiments.
$\mathrm{AB}, \mathrm{AD}, \mathrm{TK}, \mathrm{EP}, \mathrm{PR}, \mathrm{WW}$, and $\mathrm{MZ}$ performed the experiments. ER wrote the manuscript.

Acknowledgements These studies were funded by the Project OPUS 4, DEC-2012/07/B/NZ3/02917, from the Polish National Science Center.

Open Access This article is distributed under the terms of the Creative Commons Attribution 4.0 International License (http://crea tivecommons.org/licenses/by/4.0/), which permits unrestricted use, distribution, and reproduction in any medium, provided you give appropriate credit to the original author(s) and the source, provide a link to the Creative Commons license, and indicate if changes were made.

\section{References}

Allen JF (2002) Plastoquinone redox control of chloroplast thylakoid protein phosphorylation and distribution of excitation energy between photosystems: discovery, background, implications. Photosynth Res 73:139-148

Asada K (2006) Production and scavenging of reactive oxygen species in chloroplasts and their functions. Plant Physiol 141:391-396

Baena-Gonzalez E, Barbato R, Aro EM (1999) Role of phosphorylation in the repair cycle and oligomeric structure of photosystem II. Planta 208:196-204

Baker NR (2008) Chlorophyll fluorescence: a probe of photosynthesis in vivo. Annu Rev Plant Biol 59:89-113

Bradford MM (1976) A rapid and sensitive method for the quantitation of microgram quantities of protein utilizing the principle of protein-dye binding. Anal Biochem 72:248-254

Brown RH, Byrd GT (1993) Estimation of bundle sheath cell conductance in $\mathrm{C} 4$ species and $\mathrm{O}_{2}$ insensitivity of photosynthesis. Plant Physiol 103:1183-1188

Brugnoli E, Cona A, Lauteri M (1994) Xanthophyll cycle components and capacity for non-radiative energy dissipation in sun and shade leaves of Ligustrum ovalifolium exposed to conditions limiting photosynthesis. Photosynth Res 41:451-463

Chapman KSR, Hatch MD (1981) Aspartate decarboxylation in bundle sheath cells of Zea mays and its possible contribution to C4 photosynthesis. Aust J Plant Physiol 8:237-248

Dai Z, Ku MSB, Edwards GE (1995) C4 photosynthesis: the effects of leaf development on the $\mathrm{CO}_{2}$ concentrating mechanism and photorespiration in maize. Plant Physiol 107:815-825

Davies BH (1976) Carotenoids. In: Goodwin TW (ed) Chemistry and biochemistry of plants pigments, vol 2. Academic Press, London, pp 38-165

Doulis AG, Debian N, Kingston-Smith AH, Foyer CH (1997) Differential localization of antioxidants in maize leaves. Plant Physiol 114:1031-1037

Downton WJS, Pyliotis NA (1971) Loss of photosystem II during ontogeny of sorghum bundle sheath chloroplasts. Can J Bot 49:179-180

Drożak A, Romanowska E (2006) Acclimation of mesophyll and bundle sheath chloroplasts of maize to different irradiances during growth. Biochim Biophys Acta 1757:1539-1546

Foyer CH, Noctor G (2005) Redox homeostasis and antioxidant signaling: a metabolic interface between stress perception and physiological responses. Plant Cell 17:1866-1875

Foyer CH, Vanacker H, Goez LD, Harbinson J (2002) Regulation of photosynthesis and antioxidant metabolism in maize leaves at 
optimal and chilling temperatures: review. Plant Physiol Biochem 40:659-668

Friso G, Majeran W, Huang M, Sun Q, van Wijk KJ (2010) Reconstruction of metabolic pathways, protein expression, and homeostasis machineries across maize bundle sheath and mesophyll chloroplasts: large-scale quantitative proteomics using the first maize genome assembly. Plant Physiol 152:1219-1250

Furbank RT, Foyer C (1988) C4 plants as valuable model experimental system for the study of photosynthesis. New Phytol 109:265-277

Gardeström P, Wigge B (1988) Influence of photorespiration on ATP/ ADP ratios in the chloroplasts, mitochondria and cytosol, studied by rapid fractionation of barley (Hordeum vulgare) protoplast. Plant Physiol 88:69-76

Genty B, Briantais JM, Baker NR (1989) The relationship between the quantum yield of photosynthetic electron transport and quenching of chlorophyll fluorescence. Biochim Biophys Acta 990:87-92

Givnish TJ (1988) Adaptation to sun and shade: a whole-plant perspective. Aust J Plant Physiol 15:63-92

Grieco M, Suorsa M, Jajoo A, Tikkanen M, Aro EM (2015) Lightharvesting II antenna trimers connect energetically the entire photosynthetic machinery- including both photosystems II and I. Biochim Biophys Acta 1847:607-619

Hakala M, Rantamäki S, Puputti EM, Tyystjärvi T, Tyystjärvi E (2006) Photoinhibition of manganese enzymes: insights into the mechanism of photosystem II photoinhibition. J Exp Bot 57:1809-1816

Hardt H, Kok B (1978) Comparison of the photosynthetic activities of spinach chloroplasts with those of corn mesophyll and corn bundle sheath tissue. Plant Physiol 62:59-63

Hasan R, Kawasaki M, Taniguchi M, Miyake H (2006) Salinity stress induces granal development in bundle sheath chloroplasts of maize, an NADP-malic enzyme-type C4 plant. Plant Prod Sci 9:256-265

Hatch MD (1987) $C_{4}$ photosynthesis: a unique blend of modified biochemistry, anatomy and ultrastructure. Biochim Biophys Acta 895:81-106

Hatch MD, Kagawa T, Craig S (1975) Subdivision of $\mathrm{C}_{4}$-pathway species based on differing $\mathrm{C}_{4}$ acid decarboxylating systems and ultrastructural features. Aust J Plant Physiol 2:111-128

Holleboom CP, Walla PJ (2014) The back and forth of energy transfer between carotenoids and chlorophylls and its role in the regulation of light harvesting. Photosynth Res 119:215-221

Krause GH, Weis E (1991) Chlorophyll fluorescence and photosynthesis: the basics. Annu Rev Plant Physiol 42:313-349

Krupnik T, Kotabová E, van Bezouwen LS, Mazur R, Garstka M, Nixon PJ, Barber J, Kaňa R, Boekema EJ, Kargul J (2013) A reaction center-dependent photoprotection mechanism in a highly robust photosystem II from an extremophilic red alga, Cyanidioschyzon merolae. J Biol Chem 288:23529-23542

Kügler M, Jänsch L, Kruft V, Schmitz UK, Braun HP (1997) Analysis of the chloroplast protein complexes by blue-native polyacrylamide gel electrophoresis (BN-PAGE). Photosynth Res 53:35-44

Laemmli UK (1970) Cleavage of structural proteins during the assembly of the head of bacteriophage T4. Nature 227:680-685

Lindahl M, Spetea C, Hundal T, Oppenheim AB, Adam Z, Andersson B (2000) The thylakoid FtsH protease plays a role in the lightinduced turnover of the photosystem II D1 protein. Plant Cell $12: 419-431$

Mamedov F, Stefansson H, Albertsson PÅ, Styring S (2000) Photosystem II in different parts of the thylakoid membrane: a functional comparison between different domains. Biochemistry 39:10478-10486
Maxwell DP, Wang Y, McIntosh L (1999) The alternative oxidase lowers mitochondrial reactive oxygen production in plant cells. Proc Natl Acad Sci USA 96:8271-8276

Meierhoff K, Westhoff P (1993) Differential biogenesis of photosystem II in mesophyll and bundle sheath cells of monocotyledonous NADP malic enzyme-type $\mathrm{C} 4$ plants: the nonstoichiometric abundance of the subunits of photosystem II in the bundle sheath chloroplasts and the translational activity of the plastome-encoded genes. Planta 191:13-33

Meister M, Agostino A, Hatch MD (1996) The roles of malate and aspartate in $\mathrm{C} 4$ photosynthetic metabolism of Flaveria bidentis (L.). Planta 199:262-269

Mekala NR, Suorsa M, Rantala M, Aro EM, Tikkanen M (2015) Plants actively avoid state transitions upon changes in light intensity: role of light-harvesting complex II protein dephosphorylation in high light. Plant Physiol 168:721-734

Mertz RA, Brutnell TP (2014) Bundle sheath suberization in grass leaves: multiple barriers to characterization. J Exp Bot 65:3371-3380. doi:10.1093/jxb/eru 108

Minagawa J (2011) State transitions- the molecular remodeling of photosynthetic supercomplexes that controls energy flow in the chloroplast. Biochim Biophys Acta 1807:897-905

Nakamoto H, Young PS (1990) Light activation of pyruvate, orthophosphate dikinase in maize mesophyll chloroplasts: a role of adenylate energy charge. Plant Cell Physiol 31:1-6

Nishiyama Y, Allakhverdiev SI, Murata N (2006) A new paradigm for the action of reactive oxygen species in the photoinhibition of photosystem II. Biochim Biophys Acta 1757:742-749

Noctor G, Rees D, Young A, Horton P (1991) The relationship between zeaxanthin, energy-dependent quenching of chlorophyll fluorescence, and trans-thylakoid $\mathrm{pH}$ gradient in isolated chloroplasts. Biochim Biophys Acta 1057:320-330

Ohnishi N, Allakhverdiev SI, Takahashi S, Higashi S, Watanabe M, Nishiyama Y, Murata N (2005) Two-step mechanism of photodamage to photosystem II: step 1 occurs at the oxygenevolving complex and step 2 occurs at the photochemical reaction center. Biochemistry 44:8494-8499

Omoto E, Kawasaki M, Taniguchi M, Miyake H (2009) Salinity induces granal development in bundle sheath chloroplasts of NADP-malic enzyme type C4 plants. Plant Prod Sci 12:199-207

Parys E, Romanowska E, Siedlecka M (2004) Light-enhanced dark respiration in leaves and mesophyll protoplasts of pea in relation to photorespiration, respiration, and some metabolites content. Acta Physiol Plant 26:37-46

Parys E, Wasilewska W, Siedlecka M, Zienkiewicz M, Drożak A, Romanowska E (2014) Metabolic responses to lead of metallicolous and nonmetallicolous populations of Armeria maritima. Arch Environ Contam Toxicol 67:565-577

Pastori GM, Mullineaux PM, Foyer CH (2000) Post-translational regulation prevents accumulation of glutathione reductase protein and activity in the bundle sheath of maize. Plant Physiol 122:667-675

Pengelly JL, Sirault XRR, Tazoe Y, Evans JR, Furbank RT, von Caemmerer S (2010) Growth of the C4 dicot Flaveria bidentis: photosynthetic acclimation to low light through shifts in leaf anatomy and biochemistry. J Exp Bot 61:4109-4122

Pokorska B, Romanowska E (2007) Photoinhibition and D1 protein degradation in mesophyll and agranal bundle sheath thylakoids of maize. Funct Plant Biol 34:844-852

Pokorska B, Zienkiewicz M, Powikrowska M, Drożak A, Romanowska E (2009) Differential turnover of the photosystem II reaction center D1 protein in mesophyll and bundle sheath chloroplasts of maize. Biochim Biophys Acta 1787:1161-1169

Porra RJ (2002) The checkered history of the development and use of simultaneous equations for the accurate determination of chlorophylls $a$ and $b$. Photosynth Res 73:149-156 
Pribil M, Pesaresi P, Hertle A, Barbato R, Leister D (2010) Role of plastid protein phosphatase TAP38 in LHCII dephosphorylation and thylakoid electron flow. PLoS Biol 8:e1000288

Rintamäki E, Martinsuo P, Pursiheimo S, Aro EM (2000) Cooperative regulation of light-harvesting complex II phosphorylation via the plastoquinol and ferredoxin-thioredoxin system in chloroplasts. Proc Natl Acad Sci USA 97:11644-11649

Rintämaki E, Kettunen R, Aro EM (1996) Differential D1 dephosphorylation in functional and photodamaged photosystem II centers. J Biol Chem 271:14870-14875

Ritz T, Damjanović A, Schulten K, Zhang JP, Koyama Y (2000) Efficiency light harvesting through carotenoids. Photosynth Res 66:125-144

Romanowska E, Parys E (2010) Mechanical isolation of bundle sheath cell strends and thylakoids from leaves of $\mathrm{C} 4$ grasses. In: Carpentier R (ed) Methods in molecular biology. Photosynthesis research protocols. Humana Press, USA, pp 327-338

Romanowska E, Igamberdiev AU, Parys E, Gardeström PA (2002) Stimulation of respiration by $\mathrm{Pb}^{2+}$ ions in detached leaves and mitochondria of $\mathrm{C}_{3}$ and $\mathrm{C}_{4}$ plants. Physiol Plant 116:148-154

Romanowska E, Drożak A, Pokorska B, Shiell BJ, Michalski WP (2006) Organization and activity of photosystems in the mesophyll and bundle sheath chloroplasts of maize. J Plant Physiol 163:607-618

Romanowska E, Kargul J, Powikrowska M, Finazzi G, Nield J, Drożak A, Pokorska B (2008) Structural organization of photosynthetic apparatus in agranal chloroplasts of maize. J Biol Chem 283:26037-26046

Ruban AV (2009) Plants in light. Commun Integr Biol 2:50-55

Schägger H (2001) Blue-native gels to isolate protein complexes from mitochondria. Methods Cell Biol 65:231-244
Schreiber U (1983) Chlorophyll fluorescence yield changes as a tool in plant physiology. The measuring system. Photosynthesis Res 9:261-272

Shapiguzov A, Ingelsson B, Samol I, Andres C, Kessler F, Rochaix JD, Vener AV, Goldschmidt-Clermont M (2010) The PPH1 phosphatase is specifically involved in LHCII dephosphorylation and state transitions in Arabidopsis. Proc Natl Acad Sci USA 107:4782-4787

Sheen J (1999) $\mathrm{C}_{4}$ gene expression. Annu Rev Plant Phys Plant Mol Biol 50:187-217

Taniguchi Y, Taniguchi M, Kawasaki M, Miyake H (2003) Strictness of the centrifugal location of bundle sheath chloroplasts in different NADP-ME type C4 grasses. Plant Prod Sci 6:274-280

Tazoe Y, Hanba YT, Furamoto T, Noguchi K, Terashima I (2008) Relationships between quantum yield for $\mathrm{CO}_{2}$ assimilation, activity of key enzymes and $\mathrm{CO}_{2}$ leakiness in Amaranthus cruenthus, a C4 dicot, growth in high or low light. Plant Cell Physiol 49:19-29

Towbin H, Staehelin T, Gordon J (1979) Electrophoretic transfer of proteins from polyacrylamide gels to nitrocellulose sheets: procedure and some applications. Proc Natl Acad Sci USA 76:4350-4354

Ueno O, Yoshimura Y, Sentoku N (2005) Variation in the activity of some enzymes of photorespiratory metabolism in $\mathrm{C} 4$ grasses. Ann Bot 96:863-869

Walker GH, Izawa S (1979) Photosynthetic electron transport in isolated maize bundle sheath cells. Plant Physiol 63:133-138

Zienkiewicz M, Drożak A, Wasilewska W, Bacławska I, PrzedpełskaWassowicz E, Romanowska E (2015) The short-term response of Arabidopsis thaliana (C3) and Zea mays (C4) chloroplasts to red and far red light. Planta 242:1479-1493 